\title{
Controlled deposition of titanium oxide overcoats by non-hydrolytic sol gel for improved catalyst selectivity and stability
}

\author{
Florent Héroguel ${ }^{1}$, Luca Silvioli ${ }^{1}$, Yuan-Peng Du, Jeremy S. Luterbacher* \\ Laboratory of Sustainable and Catalytic Processing, Institute of Chemical Sciences and Engineering, École Polytechnique Fédérale de Lausanne (EPFL),
} CH-1015 Lausanne, Switzerland

\section{A R T I C L E I N F O}

\section{Article history:}

Received 24 August 2017

Revised 19 November 2017

Accepted 20 November 2017

\section{Keywords:}

Titania

Overcoat

Non-hydrolytic sol-gel

Bifunctional

Hydrodeoxygenation

Guaiacol

Biomass conversion

Catalyst stability

Selectivity

\begin{abstract}
A B S T R A C T
Advances in the synthetic control of surface nanostructures could improve the activity, selectivity and stability of heterogeneous catalysts. Here, we present a technique for the controlled deposition of $\mathrm{TiO}_{2}$ overcoats based on non-hydrolytic sol-gel chemistry. Continuous injection of $\mathrm{Ti}^{\mathrm{i}}\left({ }^{\mathrm{PrO}}\right)_{4}$ and $\mathrm{TiCl}_{4}$ mixtures led to the formation of conformal $\mathrm{TiO}_{2}$ overcoats with a growth rate of $0.4 \mathrm{~nm} /$ injected monolayer on several materials including high surface area SBA-15. Deposition of $\mathrm{TiO}_{2}$ on SBA-15 generated mediumstrength Lewis acid sites, which catalyzed 1-phenylethanol dehydration at high selectivities and decreased deactivation rates compared to typically used HZSM-5. When supported metal nanoparticles were similarly overcoated, the intimate contact between the metal and acid sites at the supportovercoat interface significantly increased propylcyclohexane selectivity during the deoxygenation of lignin-derived propyl guaiacol (89\% at $90 \%$ conversion compared to $30 \%$ for the uncoated catalyst). For both materials, the surface reactivity could be tuned with the overcoat thickness.
\end{abstract}

ㄷ) 2017 Elsevier Inc. All rights reserved.

\section{Introduction}

Metal oxides with uniform composition are omnipresent in catalysts and catalyst supports due to their ease of production, but their use can lead to low selectivity and stability due to the lack of precise design of their surface functionalities. Deposition of thin metal oxide layers on the surface offers the opportunity to create optimal environment on the material surface [1-6]. Multiple studies demonstrate that liquid phase sol-gel based techniques can be used for the controlled growth of oxide films [7-11]. The mild operative conditions and relatively simple equipment needed for sol-gel applications make these synthetic routes appealing, especially as scale-up is considered. However, while high levels of control have been reported for $\mathrm{SiO}_{2}$ deposition, which benefits from kinetically slow hydrolysis/condensation [13], highly reactive titanium oxide precursors prevent controlled deposition of thin oxide layers $(<50 \mathrm{~nm})$. Although remarkable results were achieved by controlling the kinetics of condensation with catalysis [14] or chelating agents [15], deposition of multiple oxide layers on chal-

\footnotetext{
* Corresponding author.

E-mail address: jeremy.luterbacher@epfl.ch (J.S. Luterbacher).

1 These authors contributed equally and are listed alphabetically.
}

lenging substrates such as high surface area mesoporous materials or supported metal nanoparticles remains a challenge [16-20].

The most versatile and powerful techniques for thin film deposition on high surface area catalyst powders such as Atomic Layer Deposition (ALD) rely at present on complex instrumentation and gas phase operations. ALD [21] is the most prominent of these techniques and has been employed to improve selectivity [22] and stabilize supported nanoparticles against sintering $[2,3,23]$. However, ALD requires cumbersome instrumentation and is difficult to scale up, especially on high surface area materials and powders. In addition, gas phase synthesis offers limited possibilities for tuning material porosity and structure compared to liquid phase synthesis. Tilley and coworkers developed a thermolytic molecular approach, which allowed the generation of multicomponent oxides such as Ti-Si [24] as well as various surface modifications [25], but deposition was limited to one molecular layer [26]. In addition to overcoating strategies, high-temperature calcination and reduction were also employed to cover Co particles with a titanium oxide layer, leading to improvements in catalyst stability and changes in selectivity thanks to strong metal-support interaction during aqueous-phase hydrogenation of furfuryl alcohol [27].

Non-hydrolytic sol-gel (NHSG) chemistry is a well-known technique for material synthesis and has been previously used for catalyst synthesis [28,29]. However, we have found limited 
use of sol-gel chemistry for the deposition of thin oxide films and its effect on catalysis. NHSG precursors were used for the layer-bylayer deposition of $\mathrm{TiO}_{2}$ on SBA-15 [30]. However, the alternated manual precursor addition for each half layer limited the control on the overcoat deposition and no effects on catalytic properties were reported. Similarly, ALD was used to deposit $\mathrm{TiO}_{2}$ films over $\mathrm{Co} / \mathrm{TiO}_{2}$ catalysts to prevent sintering and leaching of cobalt nanoparticles [31]. However, no selectivity or reactivity effects were demonstrated beyond reduced deactivation.

In this study, we introduce a new titanium oxide thin film deposition methodology based on non-hydrolytic sol-gel (NHSG) chemistry. Our deposition is carried out in a single liquid phase step involving the continuous injection of a mixture of NHSG precursors and results in uniform coatings that are comparable in conformality to those obtained with ALD, even for high surface area materials. More importantly, we demonstrate that the selectivity of both a high-surface area homogeneous oxide catalyst (SBA-15) and a supported metal catalyst $\left(\mathrm{Pt} / \mathrm{SiO}_{2}\right)$ can be significantly enhanced and controlled with the thickness of the overcoat for several reactions.

\section{Materials and methods}

\subsection{Chemicals and materials}

All reagents and solvents were analytical grade, obtained from commercial suppliers and used without further purification, unless otherwise noted. Air and moisture-sensitive reagents were handled using a nitrogen filled glove box and Schlenk techniques. Titanium isopropoxide (98\%) was obtained from Acros and distilled under reduced pressure. Titanium tetrachloride (99\%), tetramethyl orthosilicate (TMOS, 99\%), Pluronic 123 (P123, average $\mathrm{M}_{\mathrm{n}} \sim 5800$ ), styrene ( $\geq 99.5 \%)$, 3-propylguaiacol, isooctane (99\%), tetraethylorthosilicate and 1-phenylethanol (98\%) were obtained from Sigma-Aldrich. Ethanol (99\%) was obtained from Fisher Scientific. 1,4-dioxane (99.8\%) was obtained from ABCR. Hydrogen hexachloroplatinate(IV) hexahydrate $\left(\mathrm{H}_{2} \mathrm{PtCl}_{6} \cdot 6 \mathrm{H}_{2} \mathrm{O}, 99.9 \%\right)$ was obtained from Strem. Aerosil $\mathrm{TiO}_{2}$ P25 was obtained from Evonik. $\mathrm{TiO}_{2}$ PC500 was provided by Crystal. Siral40 was provided by Sasol. Toluene (VWR, 99.5\%) and diethyl ether (99\%, Fisher Scientific) were dried over sodium-benzophenone (99\%, Sigma-Aldrich), distilled and stored over $4 \AA$ Å molecular sieves (Merck) under a nitrogen atmosphere. Aqueous solutions of ammonia $\left(\mathrm{NH}_{4} \mathrm{OH}\right.$ ca. $25 \mathrm{wt}$. $\%$, ACS reagents) and hydrochloric acid ( $\mathrm{HCl}$ ca. $37 \mathrm{wt} \%$, ACS reagents) were diluted with water purified using a Millipore Milli-Q Advantage A10 water purification system to a resistivity higher than $18 \mathrm{M} \Omega \cdot \mathrm{cm}$. Synthetic air (99.999\%), hydrogen (99.999\%), helium (99.9999\%) and nitrogen (99.999\%) were obtained from Carbagas. The zeolite HZSM- 5 was obtained by calcination of $\mathrm{NH}_{4} \mathrm{ZSM}-5$ (ABCR, 23:1 mole ratio) at $550^{\circ} \mathrm{C}\left(10^{\circ} \mathrm{C} / \mathrm{min}\right.$ ramp) for $12 \mathrm{~h}$ under air flow $(100 \mathrm{~mL} / \mathrm{min})$. Silica spheres were prepared according to the Stöber process [32].

\subsection{Materials synthesis}

\subsubsection{Cuprous oxide nanoparticles synthesis}

$\mathrm{Cu}_{2} \mathrm{O}$ nanoparticles were prepared by mixing aqueous solutions $1 \mathrm{M}$ of $\mathrm{CuSO}_{4} \cdot 5 \mathrm{H}_{2} \mathrm{O}$ with $1 \mathrm{M}$ of reducing agent $\mathrm{Na}_{2} \mathrm{~S}_{2} \mathrm{O}_{3}$ in volumetric proportion of $1: 4$. The mixture was then poured into an Erlenmeyer flask containing equivolumetric amount of $1 \mathrm{M}$ sodium hydroxide. A bright orange precipitate appeared almost instantaneously, indicating that the copper was precipitating under the form of cuprous oxide. The solution was vigorously stirred for 30 min. The mixture was centrifuged and the collected particles washed four times with water and once with ethanol. The sample was then dried overnight under vacuum at $65^{\circ} \mathrm{C}$.

The materials were annealed at $200^{\circ} \mathrm{C}\left(1.5^{\circ} \mathrm{C} / \mathrm{min}\right.$ ramp $)$ for $2 \mathrm{~h}$ under inert gas $\left(\mathrm{N}_{2}\right)$ flow to increase their stability toward air oxidation. This synthetic route reportedly yields ( $\left.\begin{array}{llll}1 & 1 & 1\end{array}\right)$ planeoriented cuprous oxide nanoparticles [33].

\subsubsection{Supported platinum nanoparticle synthesis}

$\mathrm{Pt} / \mathrm{SiO}_{2}$ and $\mathrm{Pt} / \mathrm{TiO}_{2}$ were prepared by incipient wetness impregnation of the support with a $0.1 \mathrm{M} \mathrm{HCl}$ aqueous solution of $\mathrm{H}_{2} \mathrm{PtCl}_{6}-$ $.6 \mathrm{H}_{2} \mathrm{O}$, calcination at $500{ }^{\circ} \mathrm{C}$ in a muffle furnace and reduction under $\mathrm{H}_{2}$ flow $(100 \mathrm{~mL} / \mathrm{min})$ at $300{ }^{\circ} \mathrm{C}\left(2{ }^{\circ} \mathrm{C} / \mathrm{min}\right.$ ramp $)$ for $10 \mathrm{~h}$.

\subsubsection{SBA-15 synthesis}

The synthesis of mesoporous silica SBA-15 was based on methods found in literature [34-37]. Pluronic 123 (7.0 g) was dissolved in a $1.6 \mathrm{M}$ aqueous $\mathrm{HCl}$ solution $(262.5 \mathrm{~g}$ ) in a round bottom flask and heated to $35{ }^{\circ} \mathrm{C}$ in oil bath. Then, TMOS $(10 \mathrm{~mL})$ was added to start the synthesis, stirring the solution vigorously for $1 \mathrm{~min}$ followed by moderate stirring for $24 \mathrm{~h}$. Afterward, a hydrothermal treatment under static conditions at $140{ }^{\circ} \mathrm{C}$ was performed for an additional $24 \mathrm{~h}$. This was followed by filtration, and a day-long Soxhlet extraction with ethanol. The sample was then dried in a ventilated oven at $90{ }^{\circ} \mathrm{C}$ for $12 \mathrm{~h}$. Finally, the acquired solid was calcined in a muffle furnace for $6 \mathrm{~h}$ at $500{ }^{\circ} \mathrm{C}\left(1{ }^{\circ} \mathrm{C} / \mathrm{min}\right.$ ramp).

\subsubsection{Overcoating representative procedure}

The substrate $(0.5 \mathrm{~g})$ was loaded into a double neck round bottom flask and dried for $12 \mathrm{~h}$ at $150{ }^{\circ} \mathrm{C}$ under vacuum $\left(<10^{-2} \mathrm{mbar}\right)$. After refilling the flask with nitrogen, the solid was suspended in anhydrous toluene $(20 \mathrm{~mL})$ and sonicated for $10 \mathrm{~min}$ to ensure uniform particle dispersion. A reflux condenser was fitted to the flask and the suspension was stirred at $110^{\circ} \mathrm{C}$. The precursor solution was prepared under inert atmosphere by dissolving appropriate amounts of $\mathrm{TiCl}_{4}$ and freshly distilled $\mathrm{Ti}\left(\mathrm{O}^{\mathrm{i}} \mathrm{Pr}\right)_{4}$ in anhydrous toluene to yield a molar ratio $[\mathrm{Ti}] /\left[{ }^{\mathrm{i}} \mathrm{PrO}\right]=1$. Concentrations were adjusted to achieve one monolayer per $\mathrm{mL}$, calculated from the ratio of the titania precursor's projected surface area (determined from its Van der Waals volume projection as described in our previous work [38]) and the substrate surface area. The precursor solution was added to the refluxing suspension through a rubber septum using a gas-tight glass syringe (Hamilton, US) with a PTFE plunger and an automatic syringe pump (KDS 100 legacy). The needle was kept at a distance of at least $10 \mathrm{~cm}$ from the mixture to avoid premature $\mathrm{TiO}_{2}$ condensation on the needle tip (Fig. S2). The addition rate was typically set to one monolayer per hour, or 0.5 monolayer per hour for high surface area substrates $(>100$ $\mathrm{m}^{2} / \mathrm{g}$ ). After completing the precursor addition, the mixture was stirred for $2 \mathrm{~h}$ and cooled to $80^{\circ} \mathrm{C}$. Then, $20 \mathrm{~mL}$ of anhydrous diethyl ether were added to quench unreacted $\mathrm{Ti}-\mathrm{Cl}$ bonds and the mixture was stirred for another $12 \mathrm{~h}$. The solid was collected by centrifugation ( $5 \mathrm{~min}, 4500 \mathrm{rpm}$ ) and washed three times with $50 \mathrm{~mL}$ diethyl ether, twice with $50 \mathrm{~mL}$ ethanol, before being redispersed in $\mathrm{H}_{2} \mathrm{O}$. Aging of the as-synthesized overcoat was performed by stirring the material for $12 \mathrm{~h}$ at $70^{\circ} \mathrm{C}$ in an aqueous solution of $0.2 \mathrm{M} \mathrm{NH}_{4} \mathrm{OH}$. Finally, the solid was isolated by filtration, dried under vacuum at $80^{\circ} \mathrm{C}$ and calcined for $5 \mathrm{~h}$ at $500{ }^{\circ} \mathrm{C}$ $\left(2{ }^{\circ} \mathrm{C} / \mathrm{min}\right.$ ramp) under flow of synthetic air.

\subsection{Material characterization}

\subsubsection{Inductively coupled plasma optical emission spectrometry (ICP- $O E S)$}

Elemental analyses were performed at the EPFL Central Environmental Laboratory using inductively coupled plasma optical emission spectrometry (ICP-OES) on an ICPE-9000 Multitype 
Shimadzu instrument. Metals were dissolved using a 1:2 volumetric mixture of concentrated aqueous nitric acid (ca. $70 \mathrm{wt} . \%$ ) and hydrochloric acid (ca. 37 wt.\%) solutions.

\subsubsection{Transmission electron microscopy (TEM)}

The overcoat morphology was characterized by Transmission Electron Microscopy (TEM) and High-Angle Annular Dark-Field Scanning Transmission Electron Microscopy (HAADF-STEM) on a FEI Talos with $200 \mathrm{kV}$ acceleration voltage in the mode resulting in atomic number contrast ( $Z$ contrast). Lacey carbon grids were prepared by directly "dipping" the grid into the sample powder. For thickness and particle size distribution, at least 50 measurements were taken. Energy-Dispersive X-ray spectroscopy (EDXS) analysis was performed using Bruker Esprit software. Average thickness and standard deviations were calculated from STEM images using a minimum of 60 equally spaced random measurements on at least 10 different particles using ImageJ software. The resulting data was analyzed with Origin2016Pro and Igor Pro software.

\subsubsection{Magic angle spinning (MAS) solid-state nuclear magnetic resonance (sSNMR)}

MAS sSNMR spectra were recorded on a $900 \mathrm{MHz}$ Bruker Avance spectrometer equipped with a conventional double resonance CP-MAS probe using a $3.2 \mathrm{~mm}$ zirconia rotor with Vespel caps at a spinning speed of $24 \mathrm{kHz}$. ${ }^{1} \mathrm{H}$ ssNMR spectra were recorded using Hahn-Echo sequence with $2 \mathrm{~s}$ recycle delay. ${ }^{1} \mathrm{H}^{2}{ }^{29} \mathrm{Si}$ cross polarization (CP) ssNMR spectra were recorded using a contact time of $15 \mathrm{~ms}$ using Carl-Purcell-Meiboom-Gill (CPMG) sequence with a $2 \mathrm{~s}$ recycle delay. Spectra were recorded at 25 ${ }^{\circ} \mathrm{C}$. Typical ${ }^{1} \mathrm{H}-{ }^{29} \mathrm{Si}$ acquisition was 1024 scans (38 min).

\subsection{4. $N_{2}$ physisorption}

Brunauer-Emmett-Teller (BET) surface, Barrett-Joyner-Halenda (BJH) mesoporous and DFT microporous volumes were calculated from $\mathrm{N}_{2}$-physisorption measurements on a Micromeritics 3Flex apparatus at liquid nitrogen temperature between $10^{-5}$ and 0.99 relative $\mathrm{N}_{2}$ pressure. Samples (ca. $100 \mathrm{mg}$ ) were dried at $120^{\circ} \mathrm{C}$ (temperature reached with a ramp of $2^{\circ} \mathrm{C} / \mathrm{min}$ ) under vacuum $\left(<10^{-3}\right.$ mbar $)$ for $4 \mathrm{~h}$ and a leak test was performed prior to analysis.

\subsubsection{X-ray diffraction (XRD)}

Small angle XRD measurements were performed in a PANalytical Empyrean system (Theta-Theta, $240 \mathrm{~mm}$ ) equipped with parallel beam mirror optics with $\mathrm{Cu} \mathrm{K} \alpha$ as a radiation source.

\subsection{6. $\mathrm{NH}_{3}$ temperature programmed desorption}

The concentration of acid sites was calculated from $\mathrm{NH}_{3}$ temperature programmed desorption (TPD) performed on a Micromeritics Autochem 2920 II instrument. Typically, the sample (ca. $100 \mathrm{mg}$ ) was loaded to a U-shaped cell and dried for $4 \mathrm{~h}$ under He flow $(50 \mathrm{~mL} / \mathrm{min})$ at $300^{\circ} \mathrm{C}\left(2^{\circ} \mathrm{C} / \mathrm{min}\right)$. After cooling down to $50{ }^{\circ} \mathrm{C}$, the flow was switched to a $1: 99$ (volumetric ratio) $\mathrm{NH}_{3}: \mathrm{He}$ mixture for $1 \mathrm{~h}$ to saturate the sample with $\mathrm{NH}_{3}$. The sample was then flushed with $\mathrm{He}(50 \mathrm{~mL} / \mathrm{min})$ to remove physisorbed $\mathrm{NH}_{3}$ and the temperature was ramped to $500{ }^{\circ} \mathrm{C}$ at a rate of $10^{\circ} \mathrm{C} /$ min. During this process, ammonia desorption was monitored using a calibrated thermal conductivity detector as well as MKS Cirrus II mass spectrometer calibrated to mass 16 .

\subsubsection{Diffuse reflectance infrared Fourier transform spectroscopy (DRIFTS)}

DRIFT spectra were recorded using a high temperature Harrick DRIFT cell on a Perkin Elmer Frontier spectrometer equipped with a mercury cadmium telluride detector. Spectra were typically col- lected with 32 scans at a resolution of $4 \mathrm{~cm}^{-1}$. Helium $(100 \mathrm{~mL} /$ min) was passed through a bubbler filled with pyridine to saturate the samples with pyridine vapor $\left(30 \mathrm{~min}, 150^{\circ} \mathrm{C}\right)$. Physisorbed pyridine was eliminated by flowing pure helium $\left(30 \mathrm{~min}, 150^{\circ} \mathrm{C}\right.$ ) through the cell.

\subsection{Catalytic testing}

\subsubsection{1-Phenylethanol dehydration}

1-Phenylethanol dehydration was carried out in $10 \mathrm{~mL}$ Alltech glass reactors (Grace) with silicon sealing disks and PTFE screw caps. Typically, reactors were loaded with $5 \mathrm{~mL}$ of 1,4-dioxane and $15 \mathrm{mg}$ of catalyst, $200 \mu \mathrm{L}$ of 1 -phenylethanol and $50 \mu \mathrm{L}$ of dodecane (internal standard). Reactors were sonicated for $15 \mathrm{~min}$ to ensure catalyst dispersion and the reaction was started by placing reactors into the holes of an aluminum block heated by a hot plate. Low stirring speeds around $200 \mathrm{rpm}$ were employed to avoid catalyst deposition to the walls above the solvent level. $50 \mu \mathrm{L}$ aliquots were collected after cooling down the reactor in an ice bath. Samples were diluted in 1,4-dioxane (10x) and filtered. Reagent and products concentrations were determined with an Agilent Technologies 7890A Gas Chromatography (GC) apparatus equipped with a flame ionization detector (FID) and a HP-5 capillary column $(50 \mathrm{~m}, 0.32 \mathrm{~mm})$. Compound identification was performed on an Agilent Technologies 7890B series GC equipped with an HP5-MS capillary column and an Agilent 5977A series Mass Spectroscopy detector. 1-phenylethanol, dodecane and styrene were quantified by means of a calibration curve. The effective carbon number method was used to quantify ethers and dimers by using the detector response of the peak of interest compared to that of an internal standard. Details for this method, first reported and verified in our previous work [39] are given in the supporting information.

\subsubsection{3-Propyl-guaiacol hydrodeoxygenation}

The catalyst $(50 \mathrm{mg})$ was loaded into a $25 \mathrm{~mL}$ stainless-steel reactor (Parr) and a $10 \mathrm{~mL}$ isooctane solution containing $1 \mathrm{mmol}$ of substrate was added. After purging 3 times with 50 bars of $\mathrm{H}_{2}$, the $\mathrm{H}_{2}$ pressure was set to 15 bar and the temperature was ramped to $200{ }^{\circ} \mathrm{C}$ using a heating plate and heating tape controlled by an Omega PID controller. After reaction, the reactor was cooled down under a flow of air and a $50 \mu \mathrm{L}$ fraction was collected once room temperature was reached and the vessel depressurized. The aliquot was diluted 10 times with isooctane and analyzed by gas chromatography. Reaction time and substrate amount were varied to achieve different levels of conversion.

\section{Result and discussion}

\subsection{Design of the optimal titanium oxide precursor}

The first objective was to develop a liquid phase overcoating technique resulting in a conformal titanium oxide layer of controlled thickness while avoiding homogeneous nucleation. To do so, quantitative reaction of the metal oxide precursor on the substrate surface was required to maintain control over the deposition. In addition, reactivity of the precursor had to be limited to the surface. Finally, relatively fast condensation kinetics were sought to allow deposition in reasonable reaction times.

Our approach was based on the pioneering work of Vioux et al. who introduced non-hydrolytic sol-gel condensation routes to metal oxides in anhydrous conditions [40-44]. Transition metal oxides can be formed by etherolysis or alcoholysis of metal halides with ethers, alcohols or metal alkoxides. These condensations are characterized by oxo-bridging between metal atoms by 
elimination of small molecules. The alcoholysis route was not considered because condensation kinetics were too slow with metal alkoxides and too fast with metal halides. Furthermore, water generated during the condensation step would likely yield byproducts and increase rates. Etherolysis involves an intermediate alkoxide formation step that is difficult to control [41], and hence was also not chosen. To obtain the targeted reactivity, we focused on the direct condensation of metal halide $\mathrm{TiCl}_{4}$ with titanium alkoxides, while screening various reaction conditions. We achieved optimal control on the condensation for the reaction between $\mathrm{TiCl}_{4}$ and $\mathrm{Ti}\left({ }^{\mathrm{i}} \mathrm{OPr}\right)_{4}$ (titanium isopropoxide). Fast ligand recombination is known to occur in metal halides and metal alkoxides mixtures [41] but no condensation was observed at room temperature between $\mathrm{TiCl}_{4}$ and $\mathrm{Ti}\left({ }^{\mathrm{i}} \mathrm{OPr}\right)_{4}$, even after several days. Condensation kinetics increased drastically with temperature and a quantitative reaction between titanium precursors was observed within $30 \mathrm{~min}$ at $110^{\circ} \mathrm{C}$, in agreement with the report by Arnal et al. [41]. Toluene was selected as a solvent because its reflux conditions were close to this temperature and no undesired reactivity with the precursors was observed.

Next, we optimized the [ $\left.{ }^{\mathrm{i} P \mathrm{PO}}\right] /[\mathrm{Ti}]$ molar ratio as the relative amounts of metal halide and metal alkoxide substantially influenced the condensation kinetics. A ratio of [ $\left.{ }^{\mathrm{PrO}}\right] /[\mathrm{Ti}]=1$-achieved with a $3: 1 \mathrm{TiCl}_{4}: \mathrm{Ti}\left(\mathrm{O}^{\mathrm{i}} \mathrm{Pr}\right)_{4}$ molar mixture-formed primarily $\mathrm{Ti}\left(\mathrm{O}^{\mathrm{i}} \mathrm{Pr}\right)$ $\mathrm{Cl}_{3}$, as reported by Arnal et al. [40]; we observed a sol-gel induction period as low as $10 \mathrm{~min}$ at $110^{\circ} \mathrm{C}$ (refluxing toluene) that fulfilled our requirement for relatively fast condensation. We investigated the reactivity further using higher ratios $\left(\left[{ }^{\mathrm{i}} \mathrm{PrO}\right] /[\mathrm{Ti}]>1\right)$, where gelation and subsequent condensation to titanium oxide took several hours to a day, without reaching full conversion. Conversely, employing lower ratios $\left(\left[{ }^{\mathrm{P}} \mathrm{PrO}\right] /[\mathrm{Ti}]<1\right)$ resulted in low final precursor conversion due to a lack of bridging oxygen atoms. As depicted in Fig. $\mathrm{S} 1, \mathrm{Ti}\left(\mathrm{O}^{\mathrm{i} P r}\right) \mathrm{Cl}_{3}$ readily undergoes selfcondensation catalyzed by its strong Lewis acidity [45]. Hence, Ti $\left(\mathrm{O}^{\mathrm{i}} \mathrm{Pr}\right) \mathrm{Cl}_{3}$ acted as both the reactive and catalytic species during titanium oxide formation.

\subsection{Deposition of $\mathrm{TiO}_{2}$ overcoats}

The reactivity of metal precursors during the deposition of the first layer differs from the self-condensation presented earlier, because substrate surface hydroxyl groups are involved. Due to the lower reactivity of self-condensation compared to hydrolytic cleavage, we expected the precursor to react preferentially with the substrate surface. As $\mathrm{Ti}-\mathrm{Cl}$ bonds are more reactive than $\mathrm{Ti}-$ OiPr toward hydrolysis $[46,47]$, we postulated a surface condensation model where surface hydroxyls reacted primarily with the chloride ligands, leading to the formation of $\mathrm{HCl}$. Each titanium center could react with one or two hydroxyl groups, yielding a mono or bis-grafted species (Fig. 1); the coordination to 3 or 4 hydroxyl groups was not considered, as it would yield unrealistic bond strain $[48,49]$. We calculated the projected surface area of $\mathrm{Ti}\left(\mathrm{O}^{\mathrm{i}} \mathrm{Pr}\right) \mathrm{Cl}_{3}$ according to Van der Waals radius to be $0.45 \mathrm{~nm}^{2}$, while the surface of a metal oxide such as $\mathrm{SiO}_{2}$ is populated by $c a .4 \mathrm{OH} /$ $\mathrm{nm}^{2}$ after dehydroxylation under vacuum at $300{ }^{\circ} \mathrm{C}$ [50]. Therefore, surface hydroxyl groups were likely not fully consumed. Consequently, monolayer coverage was calculated by using the ratio of the precursor projected surface area and the substrate surface area. Here, we define a "layer" by analogy with ALD-i.e. as the amount of Ti precursor required to saturate the surface. Similarly to ALD, the first monolayer will not cover the surface with one continuous layer of $\mathrm{TiO}_{2}$ due to the space left behind by the precursor ligands [51].

In contrast, precursor dosing according to $\mathrm{OH}$ density, as performed by Yan et al. [30] resulted in undesired excess $\mathrm{TiO}_{2}$ formation and poor deposition control. In contrast, the formation of subsequent layers likely proceeded by direct condensation between surface titanium and precursor molecules in solution by elimination of a propyl chloride molecule.

Typical overcoating procedures such as ALD require alternated steps of substrate exposure to precursors. Here, the use of a single mixture allows us to use continuous precursor addition with an automated syringe pump (Fig. S2). Continuous addition maintained a low precursor concentration in solution, which prevented homogeneous self-condensation. Moreover, the automated process does not require the presence of an operator during deposition.

Preliminary tests showed that a high degree of condensation was achieved after $40 \mathrm{~min}$ of reaction. Hence, addition rates were set to one monolayer/hour and 0.5 monolayer/hour for substrates with surface areas below and above $100 \mathrm{~m}^{2} / \mathrm{g}$, respectively, to ensure full condensation of the precursor on the substrate surface. After deposition of the last metal oxide layer, highly reactive $\mathrm{Ti}-\mathrm{Cl}$

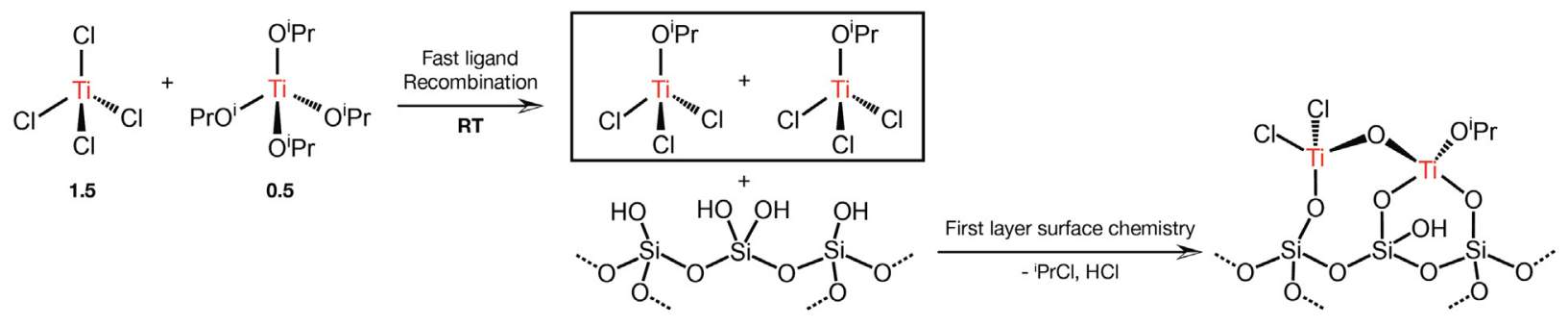

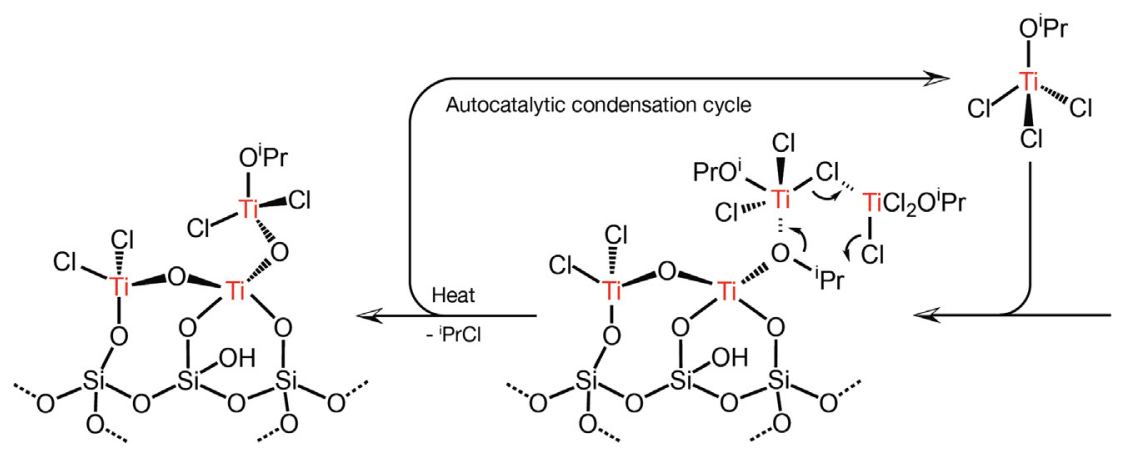

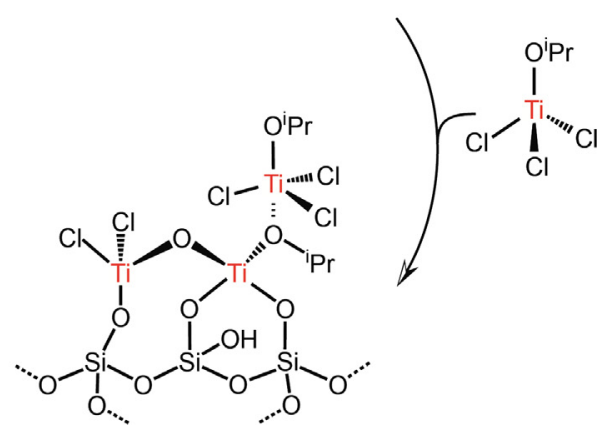

Fig. 1. Precursor formation and cycle deposition on silica surface. 
bonds remained within the coating network due to stoichiometric excess of chloride ligands during condensation. To avoid the formation of agglomerates by uncontrolled hydrolysis/condensation reactions after synthesis, the material was first quenched by refluxing in boiling anhydrous diethyl ether to exchange highly reactive chloride ligands with relatively more stable ethoxides. Further washing with non-anhydrous diethyl ether and ethanol removed the condensation by-products ${ }^{\mathrm{i}} \mathrm{PrCl}$ and $\mathrm{HCl}$ and progressively hydrolyzed ethoxide ligands to hydroxyl groups and oxobridges. Finally, full cross-linking within the metal oxide network was ensured by aging the materials in a dilute aqueous ammonia solution. Residual chlorine was detected by Energy-Dispersive Xray Spectroscopy (EDXS) (Fig. S3) but its quantitative removal was achieved after calcination under air flow at $500{ }^{\circ} \mathrm{C}$ (Fig. S4).

\subsubsection{Deposition on model $\mathrm{Cu}_{2} \mathrm{O}$ and $\mathrm{SiO}_{2}$ substrates}

$\mathrm{Cu}_{2} \mathrm{O}$ and $\mathrm{SiO}_{2}$ spheres were selected as model oxide materials because their spherical shape allows precise thickness determination by TEM. High Angle Annular Dark Field Scanning Transmission Electron Microscopy (HAADF STEM) together with EDXS mapping pictures reveal the formation of conformal overcoats after depositing $\mathrm{TiO}_{2}$ on both $\mathrm{SiO}_{2}$ and $\mathrm{Cu}_{2} \mathrm{O}$ (Fig. $2 \mathrm{~A}$ and $\mathrm{C}$ ). The deposition of $\mathrm{TiO}_{2}$ on $\mathrm{Cu}_{2} \mathrm{O}$ illustrates the compatibility of our method with substrates presenting low hydroxyl group density [52]. Coverage calculations suggest the lower limit for the surface hydroxyl density is $2 \mathrm{OH} / \mathrm{nm}^{2}$. A lower density would lead to less than full coverage and could modify the resulting deposition. The in-depth line scan profile for $30 \mathrm{TiO}_{2} @ \mathrm{Cu}_{2} \mathrm{O}$ suggests the presence of a dense overcoat located only at the surface of the substrate. $\mathrm{The}^{\mathrm{TiO}} \mathrm{O}_{2}$ signal sharply and symmetrically decreases to noise at the material interface and with distance from the substrate (Fig. 2B).
$\mathrm{TiO}_{2} @ \mathrm{Cu}_{2} \mathrm{O}$ overcoat thickness could be precisely adjusted by the number of deposited monolayers with a growth rate of 0.4 $\mathrm{nm} /$ monolayer (Fig. 2D). In addition, BET surface areas ( $\left.\mathrm{S}_{\mathrm{BET}}\right)$ calculated from $\mathrm{N}_{2}$ physisorption isotherms revealed the formation of a porous overcoat with increasing surface area for increasing overcoat thicknesses (Fig. 2D). The 20 first layers show a steep $S_{\text {BET }}$ increase from $18 \mathrm{~m}^{2} / \mathrm{g}$ for the initial $\mathrm{Cu}_{2} \mathrm{O}$ spheres to $50 \mathrm{~m}^{2} / \mathrm{g}$. From 20 layers, we observed a decrease of $\mathrm{S}_{\mathrm{BET}}$ growth rate per layer. We attributed this non-linearity to an initial surface chemistry modification effect, which gradually decreases as further layers are eventually grafted on a surface that is identical to a pure metal oxide. Furthermore, we did not observe any decrease in surface area that may be caused by particle agglomeration for high layer numbers $(>20)$. Titania loading ranged from $5.5 \mathrm{wt}$.\% for $10 \mathrm{TiO}_{2} @ \mathrm{Cu}_{2} \mathrm{O}$ to 19 wt.\% for $40 \mathrm{TiO}_{2} @ \mathrm{Cu}_{2} \mathrm{O}$ (see Tables S1 and S2 for all values). The porosity and structure of the coating can be further modified by ageing and calcination. While deposition of $15 \mathrm{TiO}_{2}$ layers on $\mathrm{SiO}_{2}$ spheres does not influence pore size distribution even after calcination at $500{ }^{\circ} \mathrm{C}$, mesoporosity around $5 \mathrm{~nm}$ is generated by ageing in basic aqueous solution $\left(0.1 \mathrm{M} \mathrm{NH}_{3}\right)$ for $12 \mathrm{~h}$ at $60^{\circ} \mathrm{C}$ (Fig. S6A). Generation of mesoporosity is accompanied by an increase of BET surface area and total pore volume (Fig. S6B). For coated samples with and without ageing, calcination causes a decrease in pore volume and surface area (Fig. S6B). Generation of mesopores is expected during $\mathrm{TiO}_{2}$ NHSG synthesis [53], we suspect the mesopores are formed after ageing due to removal of residual ligands that were blocking these pores.

\subsubsection{Deposition on high-surface area SBA-15}

To illustrate the applicability of the overcoating technique to high surface area materials, we investigated the deposition of
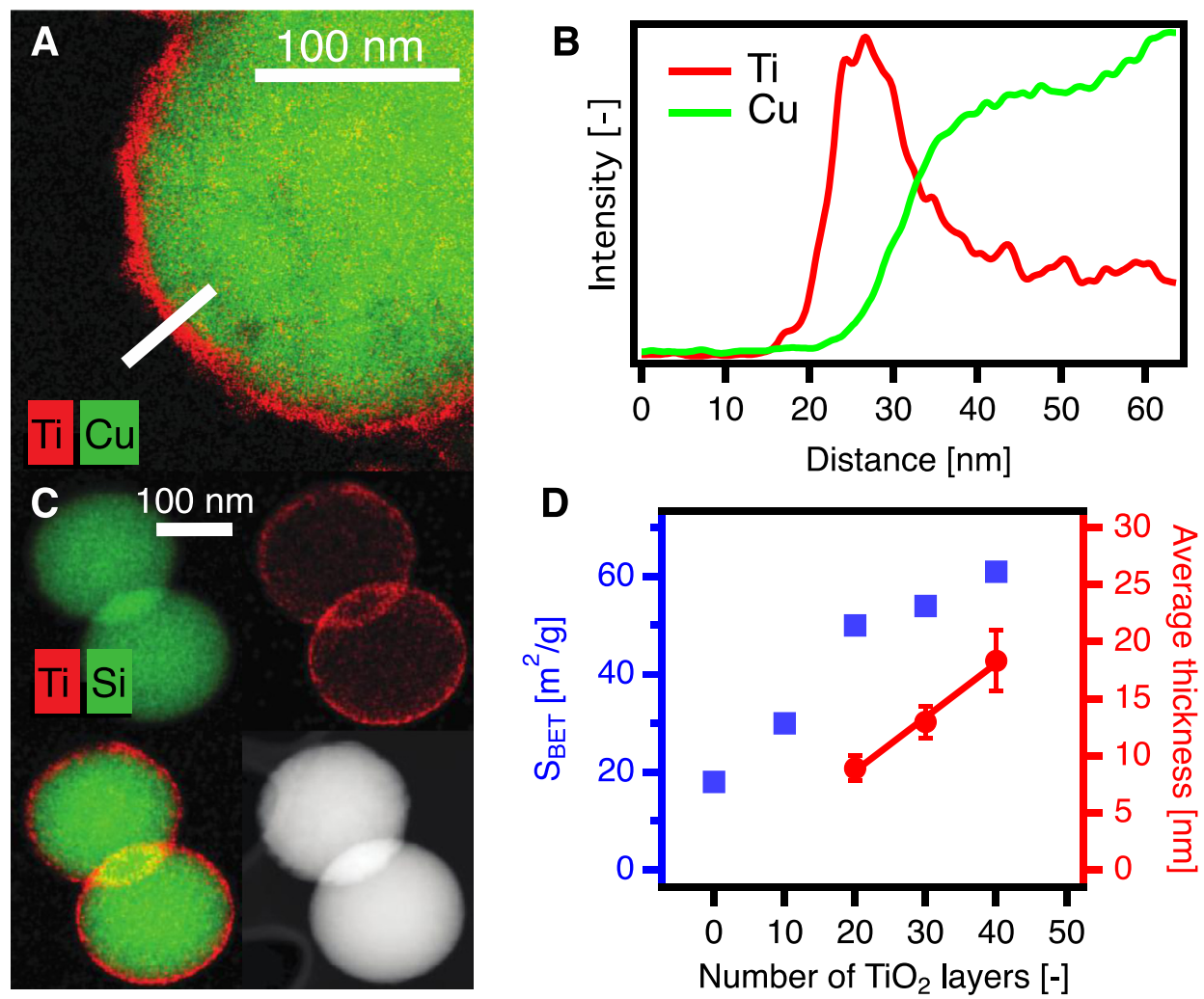

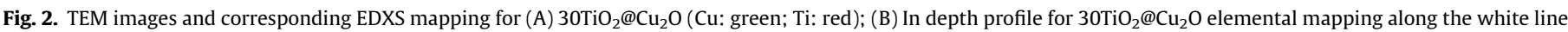

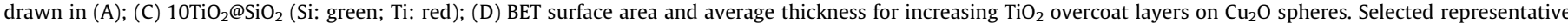

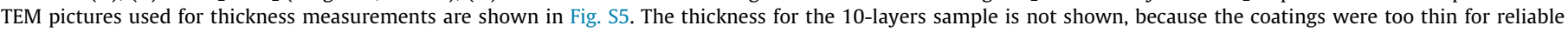
thickness measurements. 
$\mathrm{TiO}_{2}$ layers within the mesoporous structure of SBA-15 silica. We overcoated mesoporous silica with $1,2,4,6,8$ and 10 layers $\mathrm{TiO}_{2}$ using the technique described above.

Conformal overcoat deposition is typically challenging on such materials, but EDXS mapping after deposition of $10 \mathrm{TiO}_{2}$ layers clearly reveals uniform distribution of titanium into the mesopores of SBA-15, while no $\mathrm{TiO}_{2}$ aggregates were observed on SBA-15 outer surface (Fig. 3A-C). In addition, no evidence of homogeneous nucleation was detected (see Fig. S7 for additional STEM pictures and EDXS mapping at lower magnification). HAADF STEM images show retention of the $2 \mathrm{D}$ hexagonal structure with a unit-cell parameter of $10.5 \mathrm{~nm}$. EDXS line scan across the pore channels revealed coherence of $\mathrm{Si}$ and $\mathrm{Ti}$ intensities, suggesting that $\mathrm{TiO}_{2}$ layers formed during overcoating are inside $\mathrm{SiO}_{2}$ pore walls (Fig. 3D). Due to high surface area of SBA-15 $\left(690 \mathrm{~m}^{2} / \mathrm{g}\right)$, titania loading reached $68 \mathrm{wt} . \%$ after deposition of $10 \mathrm{TiO}_{2}$ layers (see Table S3 for all values).

Diffuse reflectance infrared Fourier transform spectroscopy (DRIFTS) shows a progressive red-shift of the hydroxyl group band upon deposition of $\mathrm{TiO}_{2}$ layers from $3745 \mathrm{~cm}^{-1}$ (SBA-15) to 3735 $\mathrm{cm}^{-1}\left(10 \mathrm{TiO}_{2} @ S B A-15\right.$, Fig. S8). This illustrates a transition from a surface covered by isolated silanol groups to the creation of a population of $\mathrm{Ti}-\mathrm{OH}$ groups. ${ }^{1} \mathrm{H}$ magic angle spinning (MAS) solid-state nuclear magnetic resonance (ssNMR) was investigated, as chemical shifts are very sensitive to the nature of surface hydroxyl groups [54]. The spectra of pure SBA-15 displayed a single peak at $2 \mathrm{ppm}$, which is characteristic of surface silanols. This peak was no longer observed after deposition of just one monolayer equivalent of $\mathrm{TiO}_{2}$, which was consistent with the full coverage of these silanols after deposition of the first layer (Fig. 3E). Furthermore, an additional peak was observed at 2.3 ppm for $1 \mathrm{TiO}_{2} @ S B A-15$, attributed to $=\mathrm{Si}(\mathrm{OH}) \mathrm{OTi}$ species formed by the reaction of geminal silanol $=\mathrm{Si}(\mathrm{OH})_{2}$ groups with the $\mathrm{TiO}_{2}$ precursor. This peak was no longer observed after deposition of $8 \mathrm{TiO}_{2}$ layers, consistent with the formation of a thicker $\mathrm{TiO}_{2}$ overcoat. Finally, hydroxyl groups bound to tetrahedrally coordinated $\mathrm{Ti}^{\mathrm{IV}}$ were observed around $3.3 \mathrm{ppm}$ after deposition of $\mathrm{TiO}_{2}$ [55]. Those species are characteristic of amorphous titania, while hydroxyl groups on 6coordinated $\mathrm{Ti}^{\mathrm{IV}}$ sites from anatase and rutile $\mathrm{TiO}_{2}$ phases are expected below 2.5 ppm [55].

${ }^{1} \mathrm{H}^{-29} \mathrm{Si}$ cross polarization (CP) ssNMR was investigated to probe modification of surface $\mathrm{Si}$ groups after $\mathrm{TiO}_{2}$ deposition. As opposed to single pulse ssNMR, CP ssNMR conditions highlight the surface species because this technique is more sensitive to ${ }^{29} \mathrm{Si}$ that are spatially close to surface silanols compared to bulk species. The ${ }^{1} \mathrm{H}^{29} \mathrm{Si} \mathrm{CP}$ ssNMR spectrum of pure SBA-15 (Fig. 3F) presented the 3 characteristic ${ }^{29} \mathrm{Si}$ resonances for bulk siloxanes $\left(\mathrm{Q}_{4} ;=\mathrm{Si}=\right.$; $-111 \mathrm{ppm})$, silanols $\left(\mathrm{Q}_{3} ; \equiv \mathrm{SiOH} ;-100 \mathrm{ppm}\right)$ and geminal silanols $\left(\mathrm{Q}_{2} ;=\mathrm{Si}(\mathrm{OH})_{2} ;-90 \mathrm{ppm}\right)$. After deposition of $\mathrm{TiO}_{2}$, the intensity of the $\mathrm{Q}_{2}$ peak decreased due to the transformation of germinal silanols into silanols $(=\mathrm{Si}(\mathrm{OH}) \mathrm{OTi})\left(\mathrm{Q}_{3}\right)$, in agreement with ${ }^{1} \mathrm{H}$ NMR results. The latter $\mathrm{Q}_{3}(\mathrm{Ti})$ peak, expected around $-98 \mathrm{ppm}$ [56], was most likely contributing to the broad resonance at -100 ppm. Deposition of $\mathrm{TiO}_{2}$ was also characterized by the appearance of a new peak at $-108 \mathrm{ppm}$ attributed to the formation of $\mathrm{Q}_{4}(\mathrm{Ti})$ ( $\equiv \mathrm{SiOTi}$ ) by reaction of surface $\equiv \mathrm{SiOH}\left(\mathrm{Q}_{3}\right)$ with the $\mathrm{TiO}_{2}$ precursor [56].

Overall, MAS ssNMR confirmed that the silica surface was fully covered and that hydroxyl groups were formed on amorphous $\mathrm{Ti}^{\mathrm{IV}}$ tetrahedral sites, in agreement with the absence of the crystalline $\mathrm{TiO}_{2}$ pattern in the X-ray diffractogram (Fig. S9).

Retention of the SBA-15 long-range order was further investigated by small-angle X-ray diffraction (Fig. S10). Typical SBA-15 diffraction peaks were observed at $2 \theta=0.86,1.5$ and $1.75^{\circ}$, corresponding to the (1 $\left.\begin{array}{lll}1 & 0\end{array}\right),\left(\begin{array}{lll}1 & 1 & 0\end{array}\right)$ and $\left(\begin{array}{lll}2 & 0 & 0\end{array}\right)$ reflections, respectively, consistent with $\mathrm{p} 6 \mathrm{~mm}$ symmetry of the silica mesoporous structure [57]. The intensity of the main diffraction peak at $0.86^{\circ}$ decreased gradually with the increasing number of layers. The other reflection peaks were considerably weaker and were not retained after the $\mathrm{TiO}_{2}$ overcoat deposition. Finally, d-spacing calculated from Bragg equation [58] on the main peak decreased from $10.3 \mathrm{~nm}$ (SBA-15) to $9.6 \mathrm{~nm}$ and $9.5 \mathrm{~nm}$ after deposition of 6 and
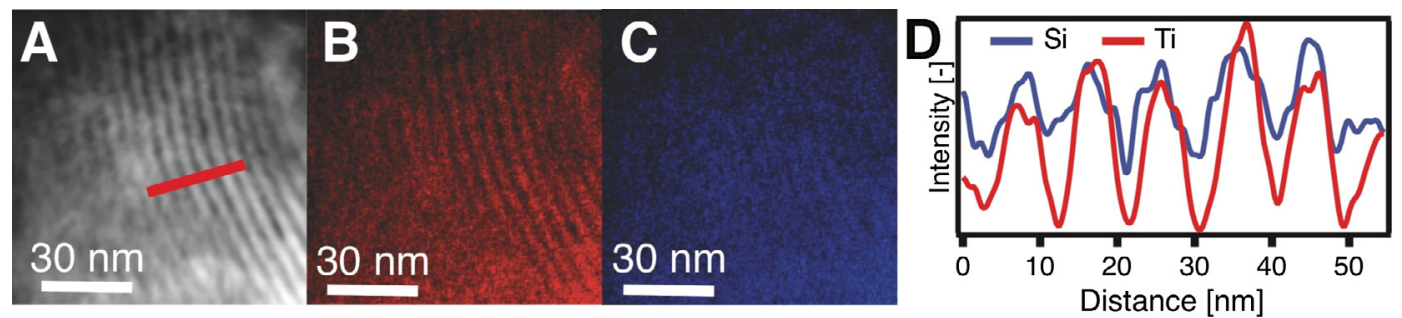

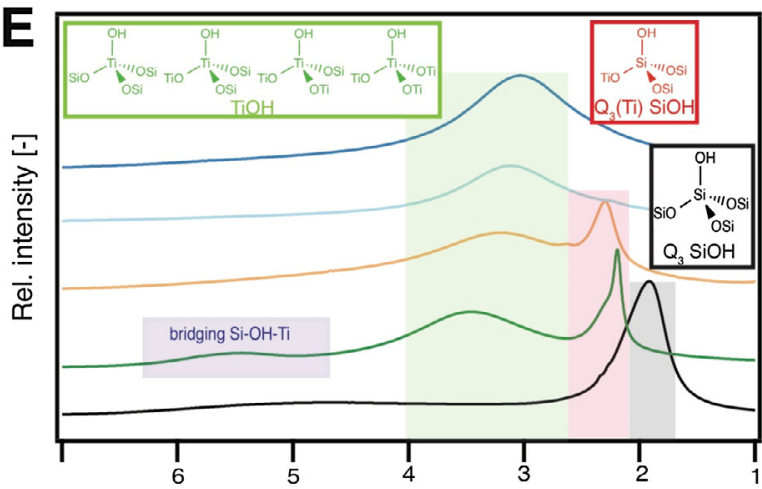

${ }^{1} \mathrm{H}$ chemical shift (ppm)

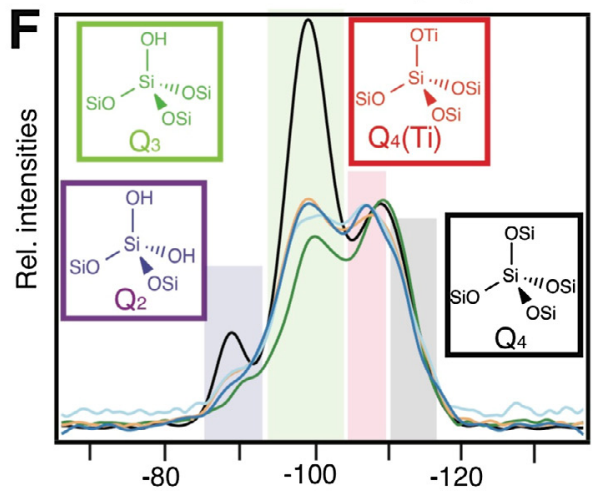

${ }^{29} \mathrm{Si}$ chemical shift (ppm)

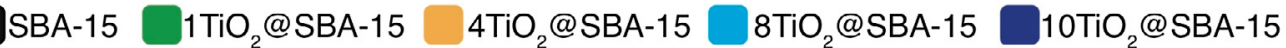

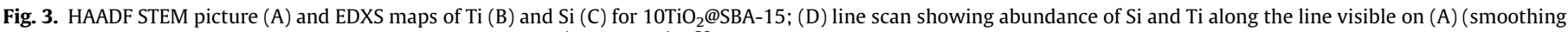

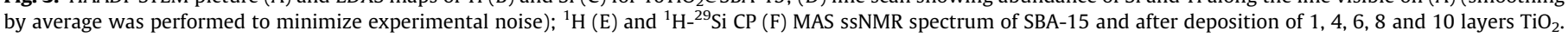




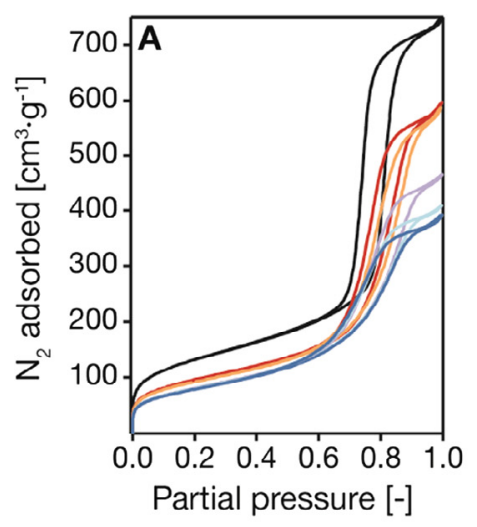

SBA-15

$2 \mathrm{TiO}_{2} @ \mathrm{SBA}-15$

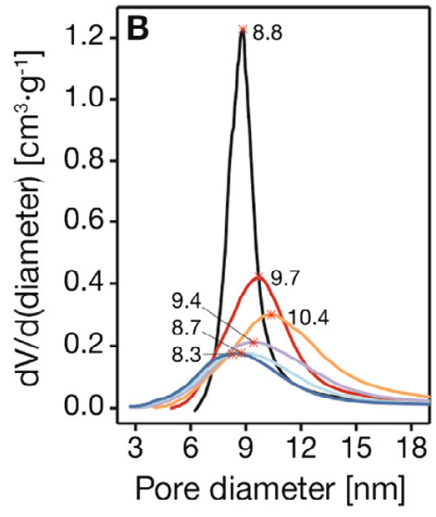

4TiO 2 @BA-15

6 $\mathrm{TiO}_{2} @ \mathrm{SBA}-15$

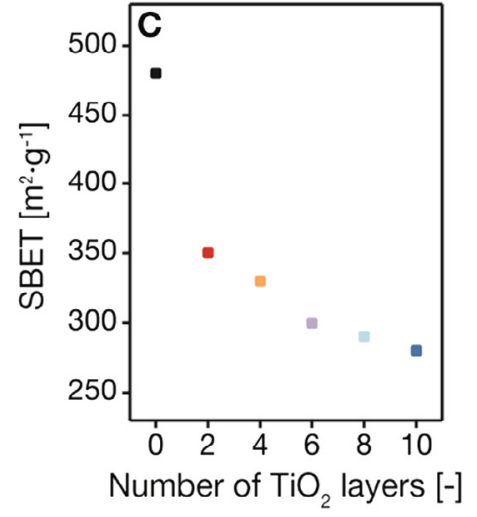

8TiO $@$ SBA-15

$10 \mathrm{TiO}_{2} @ \mathrm{SBA}-15$

Fig. 4. (A) $\mathrm{N}_{2}$ adsorption and desorption isotherms; (B) BJH pore size distributions and (C) BET surface area values for 0, 2, 4, 6, 8, 10 layers TiO $\mathrm{C}_{2} @ \mathrm{SBA}-15$.

10 layers, respectively, in agreement with STEM measurements (Fig. 3A). Perturbation of the SBA-15 diffraction pattern was expected upon overcoating, but the absence of major shift of the $\left(\begin{array}{lll}1 & 0 & 0\end{array}\right)$ reflection confirms retention of the SBA-15 structure.

Nitrogen physisorption revealed a decreasing surface area upon deposition of $\mathrm{TiO}_{2}$ layer onto SBA-15, with a drop from $480 \mathrm{~m}^{2} / \mathrm{g}$ for SBA-15 to $275 \mathrm{~m}^{2} / \mathrm{g}$ after deposition of 10 layers (Fig. 4C). The BET surface area dropped significantly after the deposition of the first two layers, which was attributed to rapid filling of micropores. DFT micropore analysis from $\mathrm{N}_{2}$ physisorption confirmed a significant decrease of microporosity compared to regular SBA-15 (Fig. S11). Gradual pores filling did not alter the pore structure, as the type $\mathrm{H} 1$ hysteresis loop observed in the isotherms was retained and is consistent with capillary pore filling associated with a mesoporous channel. Specifically, the parallel adsorption and desorption branches excluded the formation of $\mathrm{TiO}_{2}$ islands or other effects that would modify the shape of the channels (Fig. 4A). The hysteresis loop gradually lost verticality, consistent with a widening of the mesopore size distribution (Fig. 4B). We observed a light shift of the hysteresis loop toward higher partial pressure upon deposition of 2 and 4 layers, consistent with pores widening (Fig. 4B). This effect could be attributed to an increase of mean hydraulic ratio (i.e. pores volume to pore internal surface area) caused by micropore filling (i.e. sharp decrease surface area) and minimal mesopores shrinking upon deposition of first 4 layers [59]. This explanation is consistent with the line scan shown in Fig. 3D that showed incorporation of $\mathrm{TiO}_{2}$ within the channel walls. Deposition of further layers $(>6)$ lead to a mean pore diameter decrease, which was more in line with what is expected after deposition (Fig. 4A and B) [12].

\subsection{Formation of acid sites: $\mathrm{TiO}_{2} @ S B A-15$}

While SBA-15 does not have significant acidity, acidity can be generated by the formation of mixed oxide at the titania-silica interface [60]. We observed controlled acid site formation during overcoating. Ti-SBA-15 materials prepared by co-condensation of tetraethoxysilane and titanium isopropoxide have been reported $[61,62]$, but this synthesis route does not allow control of the nature of surface sites in the same way as our overcoating approach does.

Acid sites were titrated using ammonia Temperature Programmed Desorption ( $\mathrm{NH}_{3} \mathrm{TPD}$ ), which revealed the presence of acid sites characterized by a desorption peak centered around $200{ }^{\circ} \mathrm{C}$, characteristic of medium acid strength (Fig. 5A). Deposition of 2 layers $\mathrm{TiO}_{2}$ created $33 \mu \mathrm{mol}$ acid sites per gram and a maximum was reached for $6 \mathrm{TiO}_{2}$ layers with $83 \mu \mathrm{mol}$ acid sites per gram (Fig. 5B). The number of acid sites dropped after deposition of $10 \mathrm{TiO}_{2}$ layers $(35 \mu \mathrm{mol} / \mathrm{g}$ ), which is consistent with the creation of a pure $\mathrm{TiO}_{2}$ phase. As a comparison, we measured $517 \mu \mathrm{mol}$ acid sites per gram on HZSM- 5 with a second desorption peak at $300{ }^{\circ} \mathrm{C}$ attributed to strong acid sites (Fig. 5A), whereas pure $\mathrm{TiO}_{2}$ shows a broad distribution of acid strength. Pyridine adsorption monitored by Fourier Transformed Infra-Red spectroscopy was used to further identify the nature of acid sites. The use of Diffuse Reflectance (DRIFT) does not allow precise acid site quantification but density trends can be observed in addition to qualitative sites identification. While negligible interaction was observed after exposure of SBA-15 to pyridine vapor, two bands characteristic of Lewis acid sites were observed after deposition of $2 \mathrm{TiO}_{2}$ layers at 1445 and $1605 \mathrm{~cm}^{-1}$ (Fig. 5C). A third band at $1490 \mathrm{~cm}^{-1}$ can be attributed to both Lewis and Brønsted acid sites but the absence of bands at 1545 or $1640 \mathrm{~cm}^{-1}$ reveals the absence of significant Brønsted acidity on all materials [63,64]. Since Brønsted acidity in silicasupported $\mathrm{TiO}_{2}$ materials has been recently attributed to the presence of chlorides and alkoxides impurities [60,65], those data further confirmed the efficient elimination of any precursor residue from the metal oxide framework during post-synthetic treatment. The maximum intensity for the peak attributed to Lewis acid sites was observed for $6 \mathrm{TiO}_{2}$ layers where hydrogen bonding was observed as well with a band at $1590 \mathrm{~cm}^{-1}$. Beyond $6 \mathrm{TiO}_{2}$ layers, the band intensity decreased which is consistent with the formation of a pure $\mathrm{TiO}_{2}$ surface, in agreement with FTIR and SSNMR spectroscopy results. In summary, the $\mathrm{TiO}_{2}$ overcoat created a tunable number of medium strength Lewis acid sites on SBA-15 with a narrow acid strength distribution.

In view of the tunable number of medium strength Lewis acid sites generated on $\mathrm{TiO}_{2} @ S B A-15$, we investigated its use for the catalytic 1-phenylethanol dehydration, which suffers from poor yields and catalyst deactivation issues. In the past, zeolites such as HZSM-5 have been indicated as most suitable metal free catalysts for this reaction, but the presence of strong acid sites leads to fast deactivation and low selectivity due to styrene polymerization [66-68].

The reactivity of $\mathrm{TiO}_{2} @ \mathrm{SBA}-15$ was investigated at $150{ }^{\circ} \mathrm{C}$ in $1,4-$ dioxane and compared to the reference HZSM-5. The zeolite could achieve $60 \%$ selectivity at $4 \%$ conversion but selectivity dropped quickly with increasing conversion due to the formation of dimers and styrene oligomers, reaching only $12 \%$ at $99 \%$ conversion (Fig. 6A). Oligomers are not detected by gas chromatography but 

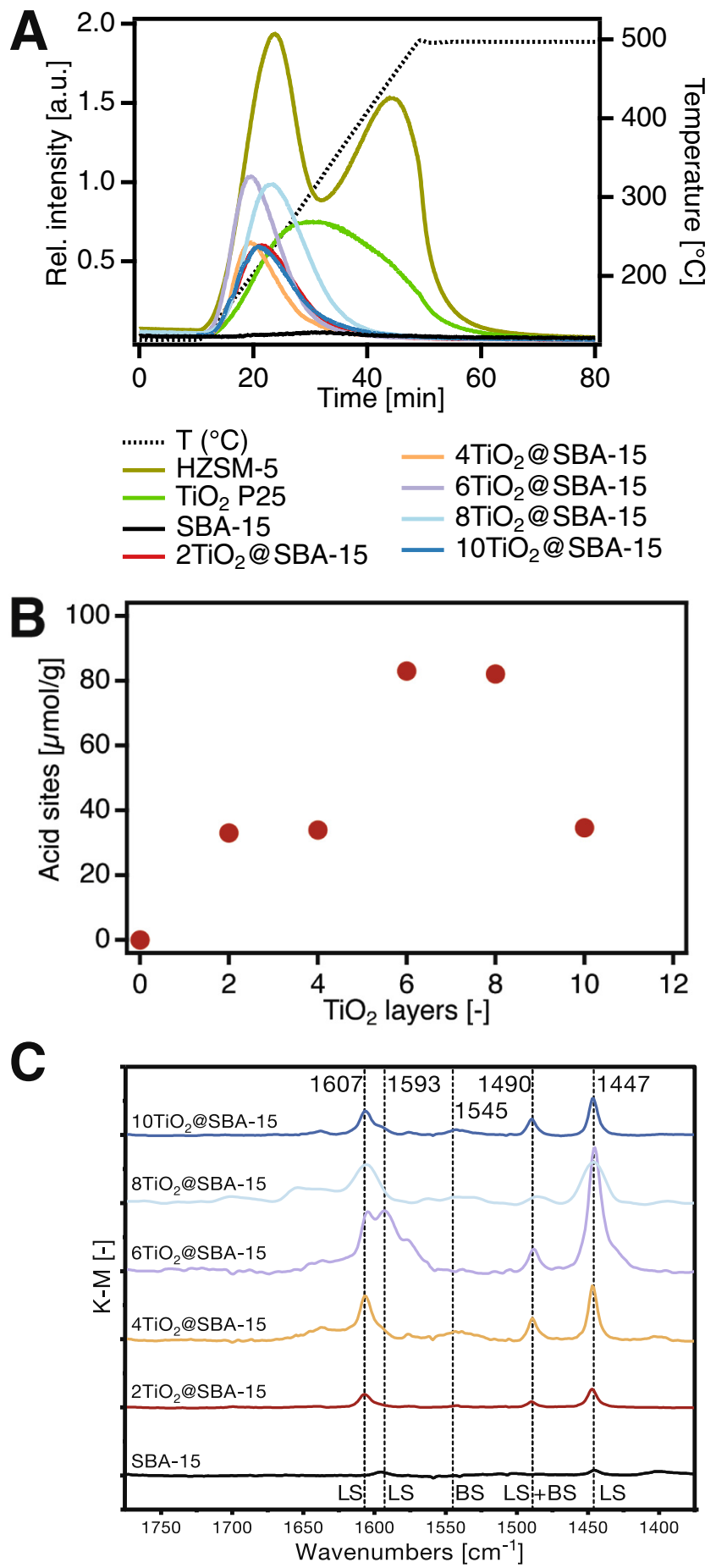

Fig. 5. $\mathrm{NH}_{3}$-Temperature Programmed Desorption graphs (A) and values (B). FTIR spectra of adsorbed pyridine on SBA-15 with increasing $\mathrm{TiO}_{2}$ layers $(\mathrm{C})$.

their presence is correlated to the decreased carbon balance and consistent with the brown color of the catalyst after reaction (Fig. S12). During a recycling study, HZSM-5 deactivated quickly with each cycle, presumably due to site blocking by oligomers (Fig. 6D). In comparison, the use of $6 \mathrm{TiO}_{2} @ \mathrm{SBA}-15$ as a catalyst led to $55 \%$ selectivity at $99 \%$ conversion (Fig. 6B). Furthermore, only little catalyst color change was observed (Fig. S12) and a recycling study showed that the rate of catalyst deactivation was much slower over the course of 4 recycles (Fig. 6D). Stability of styrene under the reaction conditions was also investigated and its conversion reached $48 \%$ within $3 \mathrm{~h}$ using the zeolite while almost 2 days were needed to reach $44 \%$ conversion with 6TiO ${ }_{2} @ S B A-15$ (Fig. S13). The fast polymerization of styrene on HZSM-5 was attributed to strong acid sites characterized by a desorption peak centered at $400{ }^{\circ} \mathrm{C}$ in $\mathrm{NH}_{3}$ TPD (Fig. 5A). Styrene polymerization on HZSM-5 can also be limited by lowering temperature to $95{ }^{\circ} \mathrm{C}$ and using cyclohexane as the solvent, as reported by Bertero et al. (reaching a $63 \%$ styrene yield compared to $57 \%$ here) [68]. Conversely, the controlled acidity on 6TiO $@$ @SBA-15 was sufficient to dehydrate phenylethanol but did not lead to fast styrene degradation.

The reactivity of $\mathrm{TiO}_{2} @ S B A-15$ was strongly related to acidity and dehydration kinetics, and gradually increased with thicker $\mathrm{TiO}_{2}$ overcoats in line with the increased number of acid sites (Table 1). The use of pure SBA-15 led to no measurable 1phenylethanol conversion. While $2 \mathrm{TiO}_{2} @ \mathrm{SBA}-15$ was not very active, activity increased with thicker layer reaching $6.7 \mathrm{mmol}$ PHE converted per gram of catalyst per min for 6TiO $\mathrm{T}_{2} @ \mathrm{SBA}-15$. Selectivity was also affected by the number of deposited layers, reaching a maximum for $8 \mathrm{TiO}_{2}$ layers $(57 \%$ at $99 \%$ conversion, Fig. 6C). Finally, $\mathrm{TiO}_{2} \mathrm{P} 25$ has slightly lower selectivity at high conversion (50\% at $99 \%$ conversion) but its activity was about $2-3$ orders of magnitude lower (Table 1).

Contrary to HZSM-5, the mesoporous structure of $\mathrm{TiO}_{2} @ S B A-15$ does not provide shape selectivity, but the formation of targeted acidity maximized activity while preventing further condensation reactions on strong acid sites. This controlled acidity led to higher selectivity and limited catalyst deactivation. Our results demonstrate that NHSG overcoating can improve catalytic selectivity by controlling the metal oxide surface functionalities.

\subsection{Metal-acid bifunctional catalysis}

We also explored the overcoating of supported metal particle catalysts to create metal and acid sites in close proximity at the interface between metal, overcoat and support. Interfacial effects are of great interest for various catalytic applications [69-71]. Specifically, we investigated the compatibility of the NHSG $\mathrm{TiO}_{2}$ deposition with the presence of Pt nanoparticles (NPs) supported on $\mathrm{SiO}_{2}$ spheres. First, platinum NPs were deposited on $\mathrm{SiO}_{2}$ spheres to form $\mathrm{Pt} / \mathrm{SiO}_{2}$, with a mean nanoparticle size of $3.3 \pm 2.1 \mathrm{~nm}\left(2.0 \mathrm{wt}\right.$ \% Pt; Fig. 7A). After deposition of $10 \mathrm{TiO}_{2}$ layers onto Pt $/ \mathrm{SiO}_{2}$, STEM (Fig. 7B and C) and EDXS mapping (Fig. 7D) showed the formation of a conformal overcoat $\left(6.1 \mathrm{wt} . \% \mathrm{TiO}_{2}\right.$, see Table S4 for all values). After deposition of $20 \mathrm{TiO}_{2}$ layers (Fig. 7E), the coating was still conformal but became coarser. The platinum particles size distribution was unaffected by deposition of $\mathrm{TiO}_{2}\left(3.6 \pm 1.3 \mathrm{~nm}\right.$ for $10 \mathrm{TiO}_{2} @ \mathrm{Pt} / \mathrm{SiO}_{2}$; see histograms in Fig. S15), attesting to the compatibility of our deposition method with the presence of metal NPs. Furthermore, the platinum particles were systematically located at the interface between the $\mathrm{SiO}_{2}$ sphere surface and the overcoat (Fig. 7C). The surface area of the materials increased linearly with the number of $\mathrm{TiO}_{2}$ layers (Fig. S16). As a control to determine the importance of having platinum located at the interfacial acid sites, platinum NPs were also deposited on $\mathrm{SiO}_{2}$ overcoated with $10 \mathrm{TiO}_{2}$ layers (denoted as $\mathrm{Pt} / 10 \mathrm{TiO}_{2} @ \mathrm{SiO}_{2}$ ), where we expected the platinum NPs to be located on the top of the $\mathrm{TiO}_{2}$ overcoat instead of at the interface between overcoat and support (Fig. 7F). In this case, the likely stronger metal-support interaction after deposition of Pt on the acidic $10 \mathrm{TiO}_{2} @ \mathrm{SiO}_{2}$ compared to pure $\mathrm{SiO}_{2}$ led to smaller NPs size $(2.0 \pm 1.0 \mathrm{~nm})$. Finally, $10 \mathrm{TiO}_{2}$ layers were deposited on $\mathrm{Pt} / \mathrm{TiO}_{2}$ to explore the importance of mixed oxide formation (sample denoted as $10 \mathrm{TiO}_{2} @ \mathrm{Pt} / \mathrm{TiO}_{2}$ ).

We investigated the performances of our bifunctional platinum/ acid sites in the hydrodeoxygenation of oxygenated aromatics derived from the lignin fraction of biomass [72-83]. The presence 

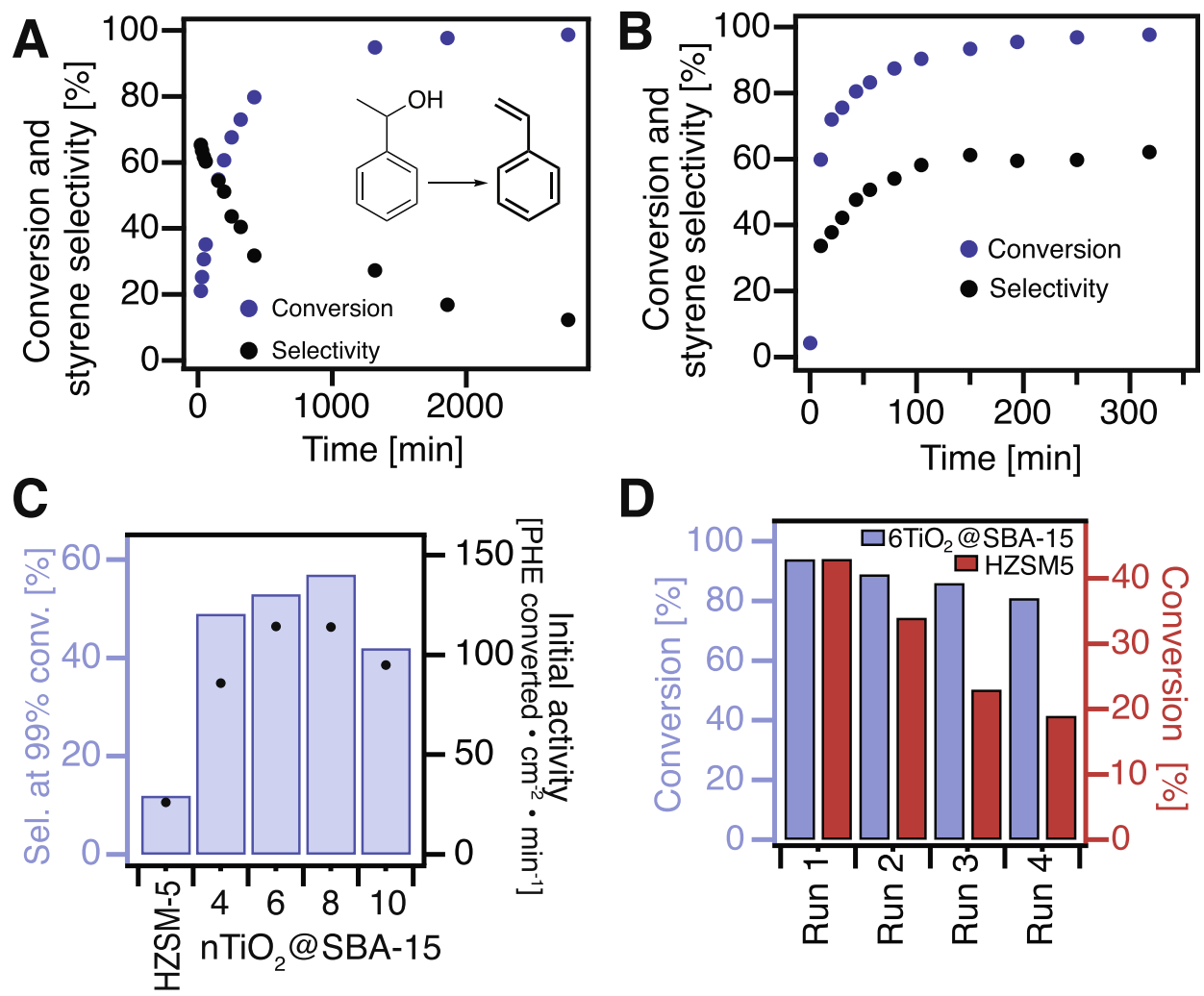

D

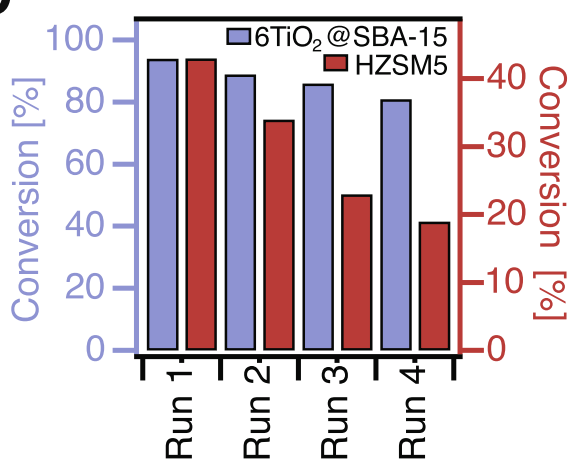

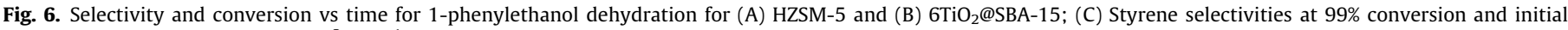

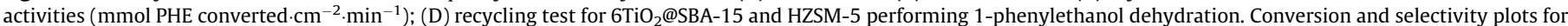
all materials are provided in Fig. S14.

Table 1

Turn Over Frequencies (TOFs) during 1-phenylethanol dehydration.

\begin{tabular}{|c|c|c|c|c|c|c|}
\hline Entry & Material & $\mathrm{S}_{\mathrm{BET}}\left(\mathrm{m}^{2} / \mathrm{g}\right)$ & 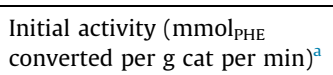 & $\begin{array}{l}\text { Initial activity (mmol } \\
\mathrm{cm}^{2} \text { cat per } \mathrm{min} \text { ) }\end{array}$ & Acid sites $(\mu \mathrm{mol} / \mathrm{g})^{\mathrm{b}}$ & $\begin{array}{l}\text { Initial TOF (mol } \\
\text { acid site per min) }\end{array}$ \\
\hline 1 & SBA-15 & 481 & 0 & 0.2 & 0 & 0 \\
\hline 2 & HZSM-5 & 385 & 1.0 & 26.1 & 517 & 1.9 \\
\hline 3 & $\mathrm{TiO}_{2} \mathrm{P} 25$ & 57 & 0.004 & 0.6 & 107 & 0.03 \\
\hline 4 & $\mathrm{TiO}_{2} \mathrm{PC} 500$ & 95 & 0.07 & 0.2 & 130 & 0.5 \\
\hline 5 & $2 \mathrm{TiO}_{2} @ S B A-15$ & 350 & 0.2 & 6.4 & 33 & 6.8 \\
\hline 6 & 4TiO ${ }_{2} @ S B A-15$ & 313 & 3.3 & 105 & 34 & 97 \\
\hline 7 & 6TiO ${ }_{2} @ S B A-15$ & 295 & 6.7 & 228 & 83 & 81 \\
\hline 8 & 8TiO ${ }_{2} @ S B A-15$ & 292 & 5.7 & 193 & 82 & 69 \\
\hline 9 & 10TiO ${ }_{2} @ S B A-15$ & 287 & 5.3 & 186 & 34 & 155 \\
\hline
\end{tabular}

a Determined using the initial slope.

b Acid sites quantified by $\mathrm{NH}_{3}$ TPD; all selectivity and conversion plots are presented in Fig. S14 as well as styrene selectivities at $80 \%$ conversion, Fig. S14g.

of acid sites close to metal nanoparticles has been shown to favor $\mathrm{C}-\mathrm{O}$ bond cleavage and therefore deoxygenation. We studied hydrodeoxygenation of 3-propylguaiacol, one of the major monomers derived from lignin depolymerisation [39] and targeted $100 \%$ selectivity of propylcyclohexane instead of a mixture of partially deoxygenated products such as substituted phenol and cyclohexanol (Fig. 8A). A reaction at $200{ }^{\circ} \mathrm{C}$ and 15 bar hydrogen in isooctane using either $\mathrm{Pt} / \mathrm{SiO}_{2}$ or $\mathrm{Pt} / \mathrm{TiO}_{2}$ yielded low selectivity to propylcyclohexane (5 and $20 \%$ for 20 and $23 \%$ conversion, respectively) with an important formation of oxygenated product at various conversions (Fig. 8A). Selectivity to propylcyclohexane is significantly higher for $10 \mathrm{TiO}_{2} @ \mathrm{Pt} / \mathrm{SiO}_{2}$ (reaching 90\% at $95 \%$ conversion) even at low conversion (selectivity of $40 \%$ at $20 \%$ conversion), clearly illustrating the benefit from the presence of Lewis acid sites in close proximity with the platinum particles. The highest selectivity was achieved for 5-10TiO $@ \mathrm{Pt} / \mathrm{SiO}_{2}$ (depending on conversion) while deposition of $2 \mathrm{TiO}_{2}$ layers only marginally improved selectivity at low conversion but was equivalent to other overcoated materials at high conversion (Fig. 8B). Interestingly, $\mathrm{Pt} / 10 \mathrm{TiO}_{2} @ \mathrm{SiO}_{2}$ and Pt/ASA (platinum particles supported on amorphous silica-alumina) led to low selectivities that were similar to the uncoated catalysts. This result emphasizes the importance of the close proximity of the metal and the Lewis acid sites, which can be achieved only when supported metal nanoparticles are overcoated (Fig. 8C). Deposition of $10 \mathrm{TiO}_{2}$ layers onto $\mathrm{Pt} /$ $\mathrm{TiO}_{2}\left(10 \mathrm{TiO}_{2} @ \mathrm{Pt} / \mathrm{TiO}_{2}\right)$ did not improve selectivity due to the absence of mixed oxide at the interface. It should be noted that the activity of the overcoated materials was significantly reduced due to partial blockage of surface metal sites by the $\mathrm{TiO}_{2}$ overcoat, dropping from $10.7 \mu \mathrm{mol} \cdot \mathrm{h}^{-1} \cdot \mathrm{g}_{\text {cat }}^{-1}$ for $\mathrm{Pt} / \mathrm{SiO}_{2}$ to $0.3 \mu \mathrm{mol} \cdot \mathrm{h}^{-1} \cdot \mathrm{g}_{\text {cat }}^{-1}$ for $2 \mathrm{TiO}_{2} @ \mathrm{Pt} / \mathrm{SiO}_{2}$ (Fig. S18). The amount of accessible Pt surface sites was titrated using volumetric CO chemisorption, and showed 


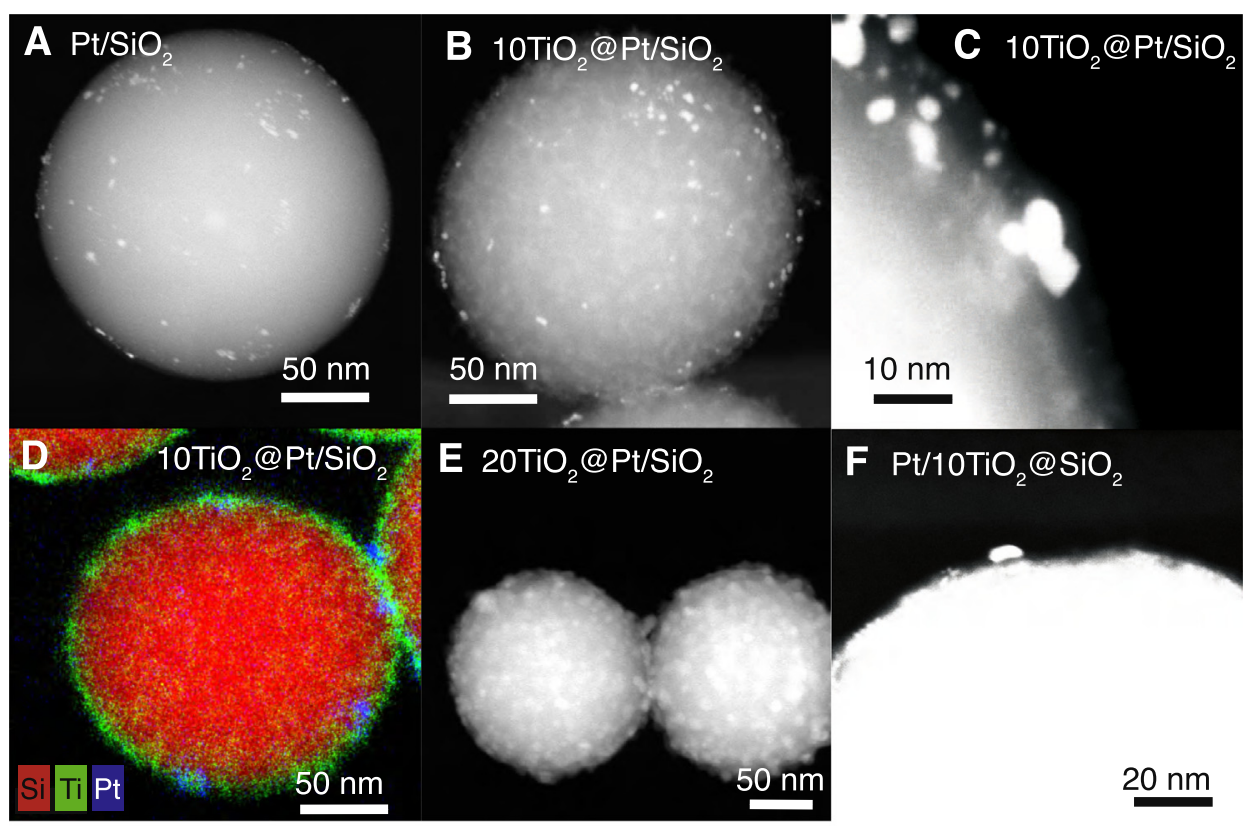

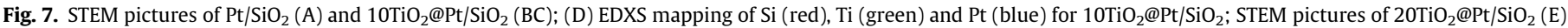

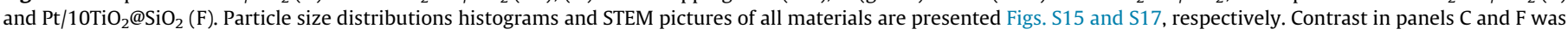
adjusted to better show the overcoat.
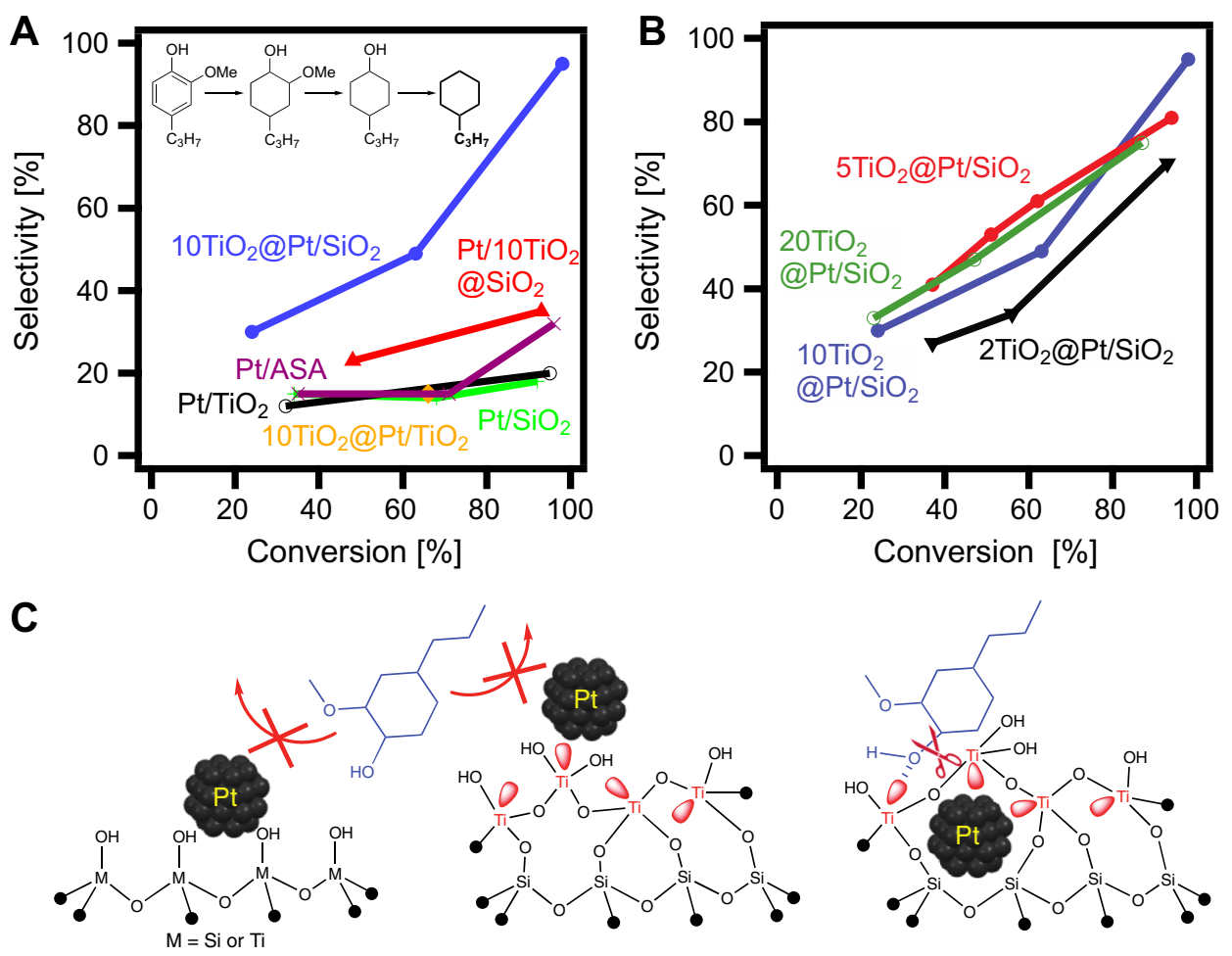

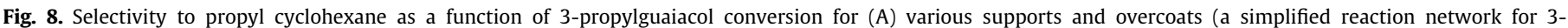

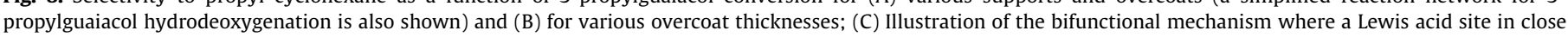
proximity to the metal allows substrate orientation and facilitated $\mathrm{C}-\mathrm{O}$ bond cleavage.

a 5-fold decrease in the ratio of accessible Pt sites after deposition of $2 \mathrm{TiO}_{2}$ layers (Fig. S19). The extent of metal coverage by the overcoat is comparable with reported ALD overcoated materials $[2,23]$, but the possibility of tuning overcoat porosity enabled by our solution phase synthesis is currently under investigation to improve metal access. Our previous work involving liquid phase overcoating with alumina further suggests that $\mathrm{TiO}_{2}$ overcoat may also be able to suppress catalyst deactivation by nanoparticle sintering [38].

\section{Conclusions}

By using NHSG chemistry, we were able to create highly conformal $\mathrm{TiO}_{2}$ overcoats over a diverse range of metal oxide and metal 
nanoparticle catalysts. The coverage of the materials, including high-surface area SBA-15 was comparable to ALD despite being an easily scalable 1 -step process in liquid phase conditions. These overcoats can be used to create acid sites at the interface with the substrate with a strength and density that can be controlled by varying the overcoating thickness. Overcoating supported metal nanoparticle catalysts led to similar sites that, because they were in close proximity to metal sites, greatly increased the catalyst's deoxygenation ability. Since we demonstrated that this method is compatible with a wide range of metal oxides, including high surface area materials and supported metal nanoparticle catalysts, we anticipate that it could be used for the post-synthesis modification of a wide variety of important catalytic materials. Finally, we propose that, because this overcoating method leads to control over the selectivity and activity of particular catalytic site, it could be especially valuable for many increasingly important biomass conversion reactions where the breadth of functional groups routinely leads to unwanted side reactions.

\section{Acknowledgments}

We thank the EPFL interdisciplinary center for electron microscopy for support during electron microscopy measurements. We acknowledge funding from the Swiss National Science Foundation through grant PYAPP2_154281 and from EPFL. We Acknowledge Emilie Baudat, Brennan J. Walder and Federico M. Paruzzo for assistance with ssNMR spectroscopy and Arnaud Magrez for assistance with XRD.

\section{Appendix A. Supplementary material}

Supplementary data associated with this article can be found, in the online version, at https://doi.org/10.1016/j.jcat.2017.11.023.

\section{References}

[1] A.C. Alba-Rubio, B.J. O’Neill, F. Shi, C. Akatay, C. Canlas, T. Li, R. Winans, J.W. Elam, E.A. Stach, P.M. Voyles, J.A. Dumesic, Pore structure and bifunctional catalyst activity of overlayers applied by atomic layer deposition on copper nanoparticles, ACS Catal. (4) (2014) 1554-1557, https://doi.org/10.1021/ cs500330p.

[2] B.J. O'Neill, D.H.K. Jackson, A.J. Crisci, C.A. Farberow, F. Shi, A.C. Alba-Rubio, J. Lu, P.J. Dietrich, X. Gu, C.L. Marshall, P.C. Stair, J.W. Elam, J.T. Miller, F.H. Ribeiro, P.M. Voyles, J. Greeley, M. Mavrikakis, S.L. Scott, T.F. Kuech, J.A. Dumesic, Stabilization of copper catalysts for liquid-phase reactions by atomic layer deposition, Angew. Chem. Int. Ed. 52 (2013) 13808-13812, https://doi. org/10.1002/anie.201308245.

[3] A. Paracchino, V. Laporte, K. Sivula, M. Grätzel, E. Thimsen, Highly active oxide photocathode for photoelectrochemical water reduction, Nat. Mater. 10 (2011) 456-461, https://doi.org/10.1038/nmat3017.

[4] X. Li, X. Liu, Y. Yang, J. Zhao, C. Li, Q. Yang, Entrapment of metal nanoparticles within nanocages of mesoporous silicas aided by co-surfactants, J. Mater. Chem. 22 (2012) 21045, https://doi.org/10.1039/c2jm33965j.

[5] B. Liu, L.-M. Liu, X.-F. Lang, H.-Y. Wang, X.W. (David) Lou, E.S. Aydil, Doping high-surface-area mesoporous $\mathrm{TiO}_{2}$ microspheres with carbonate for visible light hydrogen production, Energy Environ. Sci. 7 (2014) 2592, https://doi.org/ 10.1039/C4EE00472H.

[6] T. Stemmler, F. Chen, S. Pisiewicz, A.-E. Surkus, M.-M. Pohl, C. Topf, M. Beller, Design of N-doped graphene-coated cobalt-based nanoparticles supported on ceria, J. Mater. Chem. A. 3 (2015) 17728-17737, https://doi.org/10.1039/ C5TA02745D.

[7] D. Levy, The Sol-Gel Handbook : Synthesis, Characterization and Applications, 3-Volume Set (1), Newark, NJ, DE: John Wiley \& Sons, Incorporated, Newark, 2015.

[8] R.S. Sonawane, S.G. Hegde, M.K. Dongare, Preparation of titanium(IV) oxide thin film photocatalyst by sol-gel dip coating, Mater. Chem. Phys. 77 (2003) 744-750, https://doi.org/10.1016/S0254-0584(02)00138-4.

[9] L. Liu, D. Mandler, Sol-Gel Coatings by Electrochemical Deposition, in: Sol-Gel Handb. - Synth. Charact. Appl., Wiley Blackwell, 2015: pp. 373-414. https://doi.org/10.1002/9783527670819.ch12.

[10] G. Hodes, T. Schneller, R. Waser, M. Kosec, D. Payne, Chemical Solution Deposition of Functional Oxide Thin Films, Springer, Wien, London, 2010. https://doi.org/10.1007/978-3-211-99311-8.
[11] I. Ichinose, $\mathrm{H}$. Senzu, A surface sol-gel process of $\mathrm{TiO}_{2}$ and other metal oxide films with molecular, Chem. Mater. 4756 (1997) 1296-1298, https://doi.org/ 10.1021/cm970008g.

[12] S. Mahurin, L. Bao, W. Yan, C. Liang, S. Dai, Atomic layer deposition of $\mathrm{TiO}_{2}$ on mesoporous silica, J. Non-Cryst. Solids 352 (2006) 3280-3284, https://doi.org/ 10.1016/j.jnoncrysol.2006.05.008.

[13] F. Devreux, J.P. Boilot, F. Chaput, A. Lecomte, P. Cedex, Sol-gel condensation of rapidly hydrolyzed silicon alkoxides: a joint Si29 NMR and small-angle X-ray scattering study, Phys. Rev. A 41 (1990) 6901-6909, https://doi.org/10.1103/ PhysRevA.41.6901.

[14] W. Li, J. Yang, Z. Wu, J. Wang, B. Li, S. Feng, Y. Deng, F. Zhang, D. Zhao, A versatile kinetics-controlled coating method to construct uniform porous $\mathrm{TiO}_{2}$ shells for multifunctional core-shell structures, J. Am. Chem. Soc. 134 (2012) 11864-11867, https://doi.org/10.1021/ja3037146.

[15] K. Siwińska-Stefańska, J. Zdarta, D. Paukszta, T. Jesionowski, The influence of addition of a catalyst and chelating agent on the properties of titanium dioxide synthesized via the sol-gel method, J. Sol-Gel Sci. Technol. 75 (2015) 264-278, https://doi.org/10.1007/s10971-015-3696-2.

[16] E. Santacesaria, M. Cozzolino, M. Di Serio, A.M. Venezia, R. Tesser, Vanadium based catalysts prepared by grafting: preparation, properties and performances in the ODH of butane, Appl. Catal. A. Gen. 270 (2004) 177192, https://doi.org/10.1016/j.apcata.2004.05.003.

[17] W. Yan, S.M. Mahurin, S.H. Overbury, S. Dai, Nanoengineering catalyst supports via layer-by-layer surface functionalization, Top. Catal. 39 (2006) 199-212, https://doi.org/10.1007/s11244-006-0058-X.

[18] J. Zhang, Z. Ma, J. Jiao, H. Yin, W. Yan, E.W. Hagaman, J. Yu, S. Dai, Layer-bylayer grafting of titanium phosphate onto mesoporous silica SBA-15 surfaces: synthesis, characterization, and applications, Langmuir 25 (2009) 1254112549, https://doi.org/10.1021/la9017486.

[19] F. Zhang, X. Carrier, J.-M. Krafft, Y. Yoshimura, J. Blanchard, Insight into the structure and localization of the titania overlayer in $\mathrm{TiO}_{2}$-coated SBA-15 materials, New J. Chem. 34 (2010) 508-516, https://doi.org/10.1039/ B9NJ00439D.

[20] D. Longrie, D. Deduytsche, C. Detavernier, Reactor concepts for atomic layer deposition on agitated particles: a review, J. Vac. Sci. Technol. A 32 (2014) 10802, https://doi.org/10.1116/1.4851676.

[21] B.J. O’Neill, D.H.K. Jackson, J. Lee, C. Canlas, P.C. Stair, C.L. Marshall, J.W. Elam, T. F. Kuech, J.A. Dumesic, G.W.W. Huber, Catalyst design with atomic layer deposition, ACS Catal. 5 (2015) 1804-1825, https://doi.org/10.1021/ cs501862h.

[22] H. Zhang, X.-K. Gu, C. Canlas, A.J. Kropf, P. Aich, J.P. Greeley, J.W. Elam, R.J. Meyers, J.A. Dumesic, P.C. Stair, C.L. Marshall, Atomic layer deposition overcoating: tuning catalyst selectivity for biomass conversion, Angew. Chem. Int. Ed. 53 (2014) 12132-12136, https://doi.org/10.1002/ anie.201407236.

[23] J. Lu, B. Fu, M.C. Kung, G. Xiao, J.W. Elam, H.H. Kung, P.C. Stair, Coking- and sintering-resistant palladium catalysts achieved through atomic layer deposition, Science 335 (2012) 1205-1208, https://doi.org/ 10.1126/science.1212906.

[24] M.P. Coles, C.G. Lugmair, K.W. Terry, T.D. Tilley, Titania-silica materials from the molecular precursor $\mathrm{Ti}\left[\mathrm{OSi}(\mathrm{OtBu})_{3}\right]_{4}$ : selective epoxidation catalysts, Chem. Mater. 12 (2000) 122-131, https://doi.org/ $10.1021 / \mathrm{cm} 990444 \mathrm{y}$.

[25] K.L. Fujdala, T.D. Tilley, Design and synthesis of heterogeneous catalysts: the thermolytic molecular precursor approach, J. Catal. 216 (2003) 265-275, https://doi.org/10.1016/S0021-9517(02)00106-9.

[26] J. Jarupatrakorn, T.D. Tilley, Silica-supported, single-site titanium catalysts for olefin epoxidation. A molecular precursor strategy for control of catalyst structure, J. Am. Chem. Soc. 124 (2002) 8380-8388, https://doi.org/ $10.1021 /$ ja0202208.

[27] Jechan Lee, Samuel P. Burt, Carlos A. Carrero, Ana C. Alba-Rubio, Insoo Ro, Brandon J. O’Neill, Hyung Ju Kim, David H.K. Jackson, Thomas F. Kuech, Ive Hermans, James A. Dumesic, George W. Huber, Stabilizing cobalt catalysts for aqueous-phase reactions by strong metal-support interaction, J. Catal. 330 (2015) 19-27, https://doi.org/10.1016/j.jcat.2015.07.003.

[28] D.P. Debecker, P.H. Mutin, Non-hydrolytic sol-gel routes to heterogeneous catalysts, Chem. Soc. Rev. 41 (2012) 3624-3650, https://doi.org/10.1039/ C2CS15330K.

[29] A. Styskalik, D. Skoda, C.E. Barnes, J. Pinkas, The power of non-hydrolytic solgel chemistry: a review, Catalysts 7 (2017) 168, https://doi.org/ 10.3390/catal7060168.

[30] W. Yan, S.M. Mahurin, S.H. Overbury, S. Dai, Nonhydrolytic layer-bylayer surface sol-gel modification of powdered mesoporous silica materials with $\mathrm{TiO}_{2}$, Chem. Mater. 17 (2005) 1923-1925, https://doi.org/10.1021/ cm048118s.

[31] J. Lee, D.H.K. Jackson, T. Li, R.E. Winans, J.A. Dumesic, T.F. Kuech, G.W. Huber Enhanced stability of cobalt catalysts by atomic layer deposition for aqueousphase reactions, Energy Environ. Sci. 7 (2014) 1657-1660, https://doi.org/ 10.1039/C4EE00379A.

[32] W. Stöber, A. Fink, E. Bohn, Controlled growth of monodisperse silica spheres in the micron size range, J. Colloid Interface Sci. 26 (1968) 62-69, https://doi. org/10.1016/0021-9797(68)90272-5.

[33] L. Xiong, H. Xiao, S. Chen, Z. Chen, X. Yi, S. Wen, G. Zheng, Y. Ding, H. Yu, Fast and simplified synthesis of cuprous oxide nanoparticles: annealing studies and photocatalytic activity, RSC Adv. 4 (2014) 62115-62122, https://doi.org/ 10.1039/c4ra12406e. 
[34] A. Galarneau, H. Cambon, F. Di Renzo, F. Fajula, True microporosity and surface area of mesoporous SBA-15 silicas as a function of synthesis temperature, Langmuir 17 (2001) 8328-8335, https://doi.org/10.1021/la0105477.

[35] M. Lelli, D. Gajan, A. Lesage, M.A. Caporini, V. Vitzthum, P. Mieville, F. Héroguel, F. Rascón, A. Roussey, C. Thieuleux, M. Boualleg, L. Veyre, G. Bodenhausen, C. Copéret, L. Emsley, Fast characterization of functionalized silica materials by silicon-29 surface-enhanced NMR spectroscopy using dynamic nuclear polarization, J. Am. Chem. Soc. 133 (7) (2011) 2104-2107, https://doi.org/ 10.1021/ja110791d.

[36] T. Kjellman, N. Reichhardt, M. Sakeye, J.H. Smaištt, M. Lindén, V. Alfredsson, Independent fine-tuning of the intrawall porosity and primary mesoporosity of SBA-15, Chem. Mater. 25 (2013) 1989-1997, https://doi.org/10.1021/ cm4009442.

[37] T. Kjellman, X. Xia, V. Alfredsson, A.E.J. Garcia-Bennett, Influence of microporosity in SBA-15 on the release properties of anticancer drug dasatinib, J. Mater. Chem. B 2 (32) (2014) 5265, https://doi.org/10.1039/ C4TB00418C

[38] F. Héroguel, B.P. Le Monnier, K.S. Brown, J.C. Siu, J.S. Luterbacher, Catalyst stabilization by stoichiometrically limited layer-by-layer overcoating in liquid media, Appl. Catal. B Environ. 218 (2017) 643-649, https://doi.org/10.1016/j. apcatb.2017.07.006

[39] L. Shuai, M.T. Amiri, Y.M. Questell-Santiago, F. Héroguel, Y. Li, H. Kim, R. Meilan, C. Chapple, J. Ralph, J.S. Luterbacher, Formaldehyde stabilization facilitates lignin monomer production during biomass depolymerization, Science 354 (2016) 329-333, https://doi.org/10.1126/science.aaf7810.

[40] P. Arnal, R.J.P. Corriu, D. Leclercq, P.H. Mutin, A. Vioux, Preparation of anatase, brookite and rutile at low temperature by non-hydrolytic sol-gel methods, J. Mater. Chem. 6 (1996) 1925, https://doi.org/10.1039/jm9960601925.

[41] P. Arnal, R.J.P. Corriu, D. Leclercq, P.H. Mutin, A. Vioux, A solution chemistry study of nonhydrolytic sol-gel routes to titania, Chem. Mater. 9 (1997) 694 698, https://doi.org/10.1021/cm960337t.

[42] L. Bourget, R.J.P. Corriu, D. Leclercq, P.H. Mutin, A. Vioux, Non-hydrolytic solgel routes to silica, J. Non-Cryst. Solids 242 (2-3) (1998) 81-91, https://doi. org/10.1016/S0022-3093(98)00789-3.

[43] A. Vioux, Nonhydrolytic sol-gel routes to oxides, Chem. Mater. 9 (1997) 2292 2299, https://doi.org/10.1021/cm970322a.

[44] R.J.P. Corriu, D. Leclercq, P.H. Mutin, L. Sarlin, A. Vioux, Nonhydrolytic sol-gel routes to layered metal(IV) and silicon phosphonates, J. Mater. Chem. 8 (1998) 1827-1833, https://doi.org/10.1039/a803755h.

[45] G.A. Rasuwajew, L.M. Bobinowa, V.S. Etlis, Gewinnung und eigenshaften einiger titanorganischer verbindungen, Tetrahedron 6 (1959) 154-160, https://doi.org/10.1016/0040-4020(59)85009-2.

[46] M. Reinke, Y. Kuzminykh, P. Hoffmann, Low temperature chemical vapor deposition using atomic layer deposition chemistry, Chem. Mater. 27 (2015) 1604-1611, https://doi.org/10.1021/cm504216p.

[47] M. Rigo, P. Canu, L. Angelin, G. Della Valle, Kinetics of $\mathrm{TiCl}_{4}$ hydrolysis in a moist atmosphere, Ind. Eng. Chem. Res. 37 (1998) 1189-1195, https://doi.org/ 10.1021/ie970625e.

[48] B.A. Morrow, A.J. McFarlan, Chemical reactions at silica surfaces, J. Non-Cryst. Solids 120 (1990) 61-71, https://doi.org/10.1016/0022-3093(90) 90191-N.

[49] S. Haukka, E.-L. Lakomaa, A. Root, An IR and NMR study of the chemisorption of $\mathrm{TiCl}_{4}$ on silica, J. Phys. Chem. 97 (1993) 5085-5094, https://doi.org/10.1021/ j100121a040.

[50] L.T. Zhuravlev, The surface chemistry of amorphous silica. Zhuravlev model, Colloids Surf. A 173 (2000) 1-38, https://doi.org/10.1016/S0927-7757(00) 00556-2.

[51] C. Guerra-Nuñez, M. Döbeli, J. Michler, I. Utke, Reaction and growth mechanisms in $\mathrm{Al}_{2} \mathrm{O}_{3}$ deposited via atomic layer deposition: elucidating the hydrogen source, Chem. Mater. 29 (2017) 8690-8703, https://doi.org/10.1021 acs.chemmater.7b02759.

[52] A. Önsten, M. Göthelid, U.O. Karlsson, Atomic structure of $\mathrm{Cu}_{2} \mathrm{O}(111)$, Surf. Sci. 603 (2009) 257-264, https://doi.org/10.1016/j.susc.2008.10.048.

[53] V. Lafond, P.H. Mutin, A. Vioux, Control of the texture of titania-silica mixed oxides prepared by nonhydrolytic sol-gel, Chem. Mater. 16 (2004) 5380-5386 https://doi.org/10.1021/cm0490569.

[54] C.H.C. Liu, G.E. Maciel, The fumed silica surface: a study by NMR, J. Am. Chem. Soc. 118 (1996) 5103-5119, https://doi.org/10.1021/Ja954120w.

[55] M. Crocker, R.H.M. Herold, A.E. Wilson, M. Mackay, C.A. Emeis, A.M Hoogendoorn, ${ }^{1} \mathrm{H}$ NMR spectroscopy of titania. Chemical shift assignments for hydroxy groups in crystalline and amorphous forms of $\mathrm{TiO}_{2}$, J. Chem. Soc. Faraday Trans. 92 (1996) 2791-2798, https://doi.org/10.1039/FT9969202791.

[56] M.L. Balmer, B.C. Bunker, L.Q. Wang, C.H.F. Peden, Y. Su, Solid-state 29Si MAS NMR study of titanosilicates, J. Phys. Chem. B 101 (1997) 9170-9179, https:// doi.org/10.1021/jp971429o.

[57] D. Zhao, J. Feng, Q. Huo, N. Melosh, G. Fredrickson, B. Chmelka, G. Stucky, Triblock copolymer syntheses of mesoporous silica with periodic 50 to 300 angstrom pores, Science 279 (1998) 548-552, https://doi.org/ $10.1126 /$ science. 279.5350 .548

[58] W.H. Bragg, W.L. Bragg, The reflection of X-rays by Crystals, Proc. R. Soc. Math. Phys. Eng. Sci. 88 (1913) 428-438, https://doi.org/10.1098/rspa.1983.0054

[59] K.S.W. Sing, Reporting physisorption data for gas/solid systems with special reference to the determination of surface area and porosity (Provisional), Pure Appl. Chem. 54 (1982) 2201-2218, https://doi.org/ 10.1351/pac198254112201.
[60] J. Lu, K.M. Kosuda, R.P. Van Duyne, P.C. Stair, Surface acidity and properties of $\mathrm{TiO}_{2} / \mathrm{SiO}_{2}$ catalysts prepared by atomic layer deposition: UV-visible diffuse reflectance, DRIFTS, and visible Raman spectroscopy studies, J. Phys. Chem. C 113 (2009) 12412-12418, https://doi.org/10.1021/jp902200c.

[61] W. Ye, Z. Lin, B. Dong, J. Kang, X. Zheng, X. Wang, Preparation and catalytic properties of Ti-SBA-15 mesoporous materials, Mater. Sci. Appl. 2 (2011) 661668, https://doi.org/10.4236/msa.2011.26091.

[62] S. Alerasool, D.J. Zalewski, P.K. Doolin, S. Alerasool, D.J. Zalewski, J.F. Hoffman, Acidity studies of titania-silica mixed oxides, Catal. Lett. 25 (1994) 209-223, https://doi.org/10.1007/BF00816302.

[63] T. Kataoka, J.A. Dumesic, Acidity of unsupported and silica-supported vanadia, molybdena, and titania as studied by pyridine adsorption, J. Catal. 112 (1988) 66-79, https://doi.org/10.1016/0021-9517(88)90121-2.

[64] L. Emdadi, S.C. Oh, Y. Wu, S.N. Oliaee, Y. Diao, G. Zhu, D. Liu, The role of external acidity of meso-/microporous zeolites in determining selectivity for acidcatalyzed reactions of benzyl alcohol, J. Catal. 335 (2016) 165-174, https://doi. org/10.1016/j.jcat.2015.12.021.

[65] B. Notari, R.J. Willey, M. Panizza, G. Busca, Which sites are the active sites in $\mathrm{TiO}_{2}-\mathrm{SiO}_{2}$ mixed oxides?, Catal Today 116 (2006) 99-110, https://doi.org/ 10.1016/j.cattod.2006.02.086.

[66] J.-P. Lange, V. Otten, Dehydration of phenyl-ethanol to styrene: zeolite catalysis under reactive distillation, J. Catal. 238 (2006) 6-12, https://doi. org/10.1016/j.jcat.2005.11.033.

[67] J.P. Lange, V. Otten, Dehydration of phenyl ethanol to styrene under reactive distillation conditions: understanding the catalyst deactivation, Ind. Eng. Chem. Res. 46 (2007) 6899-6903, https://doi.org/10.1021/ie070397g.

[68] N.M. Bertero, A.F. Trasarti, C.R. Apesteguía, A.J. Marchi, Liquid-phase dehydration of 1-phenylethanol on solid acids: influence of catalyst acidity and pore structure, Appl. Catal. Gen. 458 (2013) 28-38, https://doi.org/ 10.1016/j.apcata.2013.03.018.

[69] S.D. Lin, M.A. Vannice, Hydrogenation of aromatic-hydrocarbons over supported Pt catalysts. 3. Reaction models for metal-surfaces and acidic sites on oxide supports, J. Catal. 143 (1993) 563-572, https://doi.org/10.1006/ Jcat.1993.1299.

[70] M.F. Williams, B. Fonfe, C. Woltz, A. JentyS, J.A.R. van Veen, J.A. Lercher, Hydrogenation of tetralin on silica-alumina-supported Pt catalysts II. Influence of the support on catalytic activity, J. Catal. 251 (2007) 497-506, https://doi. org/10.1016/J.Jcat. 2007.06.010.

[71] F. Héroguel, G. Siddiqi, M.D. Detwiler, D.Y. Zemlyanov, O. Safonova, C. Copéret, Simultaneous generation of mild acidic functionalities and small supported Ir NPs from alumina-supported well-defined iridium siloxide, J. Catal. 321 (2015) 81-89, https://doi.org/10.1016/j.jcat.2014.11.002.

[72] S. Echeandia, P.L. Arias, V.L. Barrio, B. Pawelec, J.L.G. Fierro, Synergy effect in the HDO of phenol over Ni-W catalysts supported on active carbon: effect of tungsten precursors, Appl. Catal. B Environ. 101 (2010) 1-12, https://doi.org/ 10.1016/j.apcatb.2010.08.018

[73] K.L. Deutsch, B.H. Shanks, Hydrodeoxygenation of lignin model compounds over a copper chromite catalyst, Appl. Catal. A gen. 447-448 (2012) 144-150, https://doi.org/10.1016/j.apcata.2012.09.047.

[74] W. Zhang, J. Chen, R. Liu, S. Wang, L. Chen, K. Li, Hydrodeoxygenation of ligninderived phenolic monomers and dimers to alkane fuels over bifunctional zeolite-supported metal catalysts, ACS Sustain. Chem. Eng. 2 (2014) 683-691, https://doi.org/10.1021/sc400401n.

[75] J.Y. He, C. Zhao, J.A. Lercher, Impact of solvent for individual steps of phenol hydrodeoxygenation with Pd/C and HZSM-5 as catalysts, J. Catal. 309 (2014) 362-375, https://doi.org/10.1016/J.Jcat. 2013.09.009.

[76] J. He, C. Zhao, D. Mei, J.A. Lercher, Mechanisms of selective cleavage of C-O bonds in di-aryl ethers in aqueous phase, J. Catal. 309 (2014) 280-290, https:// doi.org/10.1016/j.jcat.2013.09.012.

[77] M.B. Griffin, G.A. Ferguson, D.A. Ruddy, M.J. Biddy, G.T. Beckham, J.A. Schaidle, Role of the support and reaction conditions on the vapor-phase deoxygenation of m-cresol over Pt/C and Pt/TiO 2 catalysts, ACS Catal. 6 (2016) 2715-2727, https://doi.org/10.1021/acscatal.5b02868.

[78] Z. Luo, Y. Wang, M. He, C. Zhao, Precise oxygen scission of lignin derived aryl ethers to quantitatively produce aromatic hydrocarbons in water, Green Chem. 18 (2016) 433-441, https://doi.org/10.1039/C5GC01790D.

[79] T.-S. Nguyen, D. Laurenti, P. Afanasiev, Z. Konuspayeva, L. Piccolo, Titaniasupported gold-based nanoparticles efficiently catalyze the hydrodeoxygenation of guaiacol, J. Catal. 344 (2016) 136-140, https://doi. org/10.1016/j.jcat.2016.09.016.

[80] P.M. de Souza, L. Nie, L.E.P. Borges, F.B. Noronha, D.E. Resasco, Role of oxophilic supports in the selective hydrodeoxygenation of m-cresol on Pd catalysts, Catal. Lett. 144 (2014) 2005-2011, https://doi.org/10.1007/s10562-014-1337$\mathrm{y}$.

[81] Q. Tan, G. Wang, A. Long, A. Dinse, C. Buda, J. Shabaker, D.E. Resasco, Mechanistic analysis of the role of metal oxophilicity in the hydrodeoxygenation of anisole, J. Catal. 347 (2017) 102-115, https://doi.org/ 10.1016/j.jcat.2017.01.008

[82] M.-Y. Chen, Y.-B. Huang, H. Pang, X.-X. Liu, Y. Fu, Hydrodeoxygenation of lignin-derived phenols into alkanes over carbon nanotube supported $\mathrm{Ru}$ catalysts in biphasic systems, Green Chem. 17 (2015) 1710-1717, https://doi. org/10.1039/C4GC01992J.

[83] X. Zhu, L.L. Lobban, R.G. Mallinson, D.E. Resasco, Bifunctional transalkylation and hydrodeoxygenation of anisole over a Pt/HBeta catalyst, J. Catal. 281 (2011) 21-29, https://doi.org/10.1016/j.jcat.2011.03.030. 